\title{
Analysis of Limit Cycle Oscillation Data from the Aeroelastic Test of the SUGAR Truss-Braced Wing Model
}

\author{
Robert E. Bartels, ${ }^{*}$ Christie Funk ${ }^{\dagger}$ and Robert C. Scott, ${ }^{\dagger}$
}

\begin{abstract}
Research focus in recent years has been given to the design of aircraft that provide significant reductions in emissions, noise and fuel usage. Increases in fuel efficiency have also generally been attended by overall increased wing flexibility. The truss-braced wing (TBW) configuration has been forwarded as one that increases fuel efficiency. The Boeing company recently tested the Subsonic Ultra Green Aircraft Research (SUGAR) Truss-Braced Wing (TBW) wind-tunnel model in the NASA Langley Research Center Transonic Dynamics Tunnel (TDT). This test resulted in a wealth of accelerometer data. Other publications have presented details of the construction of that model, the test itself, and a few of the results of the test. This paper aims to provide a much more detailed look at what the accelerometer data says about the onset of aeroelastic instability, usually known as flutter onset. Every flight vehicle has a location in the flight envelope of flutter onset, and the TBW vehicle is not different. For the TBW model test, the flutter onset generally occured at the conditions that the Boeing company analysis said it should. What was not known until the test is that, over a large area of the Mach number dynamic pressure map, the model displayed wing/engine nacelle aeroelastic limit cycle oscillation (LCO). This paper dissects that LCO data in order to provide additional insights into the aeroelastic behavior of the model.
\end{abstract}

\section{Introduction}

Considerable research attention has been given in recent years to the design of aircraft that provide significant reductions in emissions, noise and fuel usage. The use of modern structural optimization methods combined with new materials and manufacturing techniques to achieve these metrics has enabled designers to consider non-traditional aircraft configurations. Increases in fuel efficiency usually have been achieved among other means by reducing structural weight. This approach has also resulted in overall increased wing flexibility.

The reduction of structural weight has obvious advantages with regard to reducing fuel use, but at some point, the consideration of the simultaneous interaction of aerodynamics, structures and possibly of the control system will be pressed upon the designers of such a vehicle. This will require multidisciplinary methods. Such a coupling of methods allows the designer to take advantage of the aeroelastically deformed wing shape in achieving, for instance, optimal aerodynamics for drag reduction. Besides the advantages that are opened up by a very flexible vehicle such as active wing shaping for minimizing drag, potential aeroelastic issues also arise such as excessive gust loading, an unacceptable flutter margin to be potentially allieviated by a flutter suppression system, and destablizing aero-servoelastic coupling.

The NASA Fixed Wing program funded a Phase I research grant to The Boeing Company, which identified the truss-braced wing as the best option for reducing fuel usage. That vehicle was designated the Subsonic Ultra Green Aircraft Research (SUGAR) Truss-Braced Wing (TBW) aircraft. The truss-braced wing (TBW) configuration advances the fuel efficiency metric by its large aspect ratio, wing span and by thinner wings. The increase in aspect ratio results in a reduction of induced drag. Transonic wave drag and parasite drag are lower because a thinner wing alleviates the need for wing sweep resulting in laminar flow over a greater portion of the wing.

The structural advantage of the TBW vehicle is its superior load bearing potential. The multiple load paths of a strut and jury reduce the bending moment supported by the inner wing and allow an inboard wing box to be lighter and thinner and thus, more flexible. This complex load path and more flexible inboard wing can have a significant impact on the aeroelastic behavior of the vehicle. In addition, there is a smaller body of engineering experience designing a wing with strut and jury. This increases uncertainty in the design. Uncertainty about the performance of a truss-braced

\footnotetext{
${ }^{*}$ Senior Aerospace Engineer, Aeroelasticity Branch, NASA Langley Research Center, Hampton, VA, AIAA Senior Member.

$\dagger$ Aerospace Engineer, Aeroelasticity Branch, NASA Langley Research Center, Hampton, VA, AIAA Member.

${ }^{\ddagger}$ Senior Aerospace Engineer, Aeroelasticity Branch, NASA Langley Research Center, Hampton, VA, AIAA Associate Fellow.
} 
wing structure, particularly with respect to flutter onset, motivated the development of an aeroelastic wind-tunnel test. The Boeing Company designed an aeroelastic wind-tunnel model and performed testing of it in the NASA Langley Transonic Dynamics Tunnel (TDT) in the December 2013-April 2014 time frame.

That test resulted in a large data base from which estimates of flutter onset boundaries were derived. Several papers have already addressed various aspects of the SUGAR wind-tunnel test. Bartels et al. presented a few select experimental data points several months after the completion of the test. ${ }^{2}$ A more detailed discussion of the test and development of the wind-tunnel model are presented by Allen et al. ${ }^{3}$ Additional details regarding the flutter testing, development and implementation of flutter suppression control laws, and their use in the aeroservoelastic testing of the SUGAR model was reported by Scott et al. ${ }^{4}$ Each of those papers identified stable and unstable test points. Unstable points were defined as conditions at which the excessively large amplitude motion required a tunnel flow shut-down in order to protect the model. These have also been called, and will hereafter be called hard flutter points. The Mach number/dynamic pressure region in which hard flutter points were observed has been documented in those papers.

What has not been documented are the varying states of moderate to high dynamics through which the vehicle passed as the hard flutter points were approached. A mapping of the various levels of dynamics short of hard flutter would perhaps add some insight into the nature of the dynamic response of the model. Likewise modal participation and the regions in which those modal excitations occured would be valuable. These insights would be helpful for the validation of the analytical tools (e.g., CFD) that will surely be necessary in the further development of such a vehicle. It is for these reasons that the current paper is written.

When one attempts to dissect the dynamic response of a transonic flutter model, it is soon realized that transonic flutter testing is a challenging endeavor. See reference 5 for evidence of this. Many test conditions reveal a variability in the dynamics of the aeroelastic response. Variability in the model dynamics can be due to slight changes in the aerodynamic state, such as variability in Mach number and dynamic pressure. That variability can be magnified dramatically when a model is near flutter onset. It is there that often isolated bursts of large amplitude oscillation may be seen. For instance, dynamics of this sort were reported in the transonic aereolastic test of a transport wing. ${ }^{5}$

Apart from random excitations from tunnel turbulence, one can identify different types of variability such as bursting, limit cycle oscillation (LCO) and beating responses. ${ }^{5}$ Transonic conditions add to these sources of variability by the appearance of flowfield shocks and shock separation. The dynamics of a flexible wing is very sensitive to the location and strength of a shock and separation.

All of these factors make it exceedingly difficult to extract any sort of meaningful aggregate behavior of the model. Root mean square (RMS) of responses are frequently used as a measure of the level of dynamics. However, when a signal is highly variable, an RMS of responses does not provide much about the changes that take place from a low to a high amplitude response. It also does not distinguish what frequencies contain the energy, if a specific frequency is of interest, or how the response at that frequency changes over time.

In the present paper, the digital data base from the SUGAR test has been scrutinized in order to compile a map of LCO magnitudes as a function of Mach number and dynamic pressure. Such a map has been compiled recently by Edwards for a transport wing. ${ }^{5}$ That map was compiled by visually inspecting strip chart recordings. In the present paper, digital analyses have replaced visual inspection. A windowing approach is used to deal with the variability in the model dynamics. The hundreds of test points have been separated into short, non-overlapping samples. This approach allows discarding unwanted portions and distinguishing the usable portions by Mach number, dynamic pressure and level of dynamics. The complete set is comprised of thousands of samples. Although the samples cannot be considered statistically independent, they can be treated as essentially time invariant snap shots. The compilation of these data samples will enable a mapping of model dynamics as a function of Mach number and dynamic pressure.

\section{Transonic Dynamics Tunnel (TDT) and SUGAR wind-tunnel model}

The Langley TDT is dedicated to identifying, understanding, and solving relevant aeroelastic and aeroservoelastic problems. In the present test, the tunnel used heavy gas as the test medium. In either air or heavy gas, the TDT can operate at total pressures from near vacuum to atmospheric. It has a Mach number range from near zero to 1.2 and is capable of maximum unit Reynolds numbers of about 3 million per foot in air and 10 million per foot in heavy gas. The TDT currently uses 1,1,1,2-Tetrafluoroethane (R-134a) as a heavy gas test medium. The TDT is specially configured for flutter testing with excellent model visibility from the control room and a rapid tunnel shutdown capability for model safety. Because the TDT is devoted to flutter testing, it has a by-pass valve system that rapidly decreases the test section dynamic pressure by equalizing the pressure between the test section and the back leg of the tunnel. The by-pass valve can be activated by test personnel who are monitoring model activity.

A photo of the SUGAR model in the TDT is shown in Figure 1. The development of the Boeing SUGAR TBW 
wind-tunnel model is described in reference 1 . The wing and mount system for the SUGAR TBW test were designed and fabricated by NextGen Aeronautics in Torrance, California. Details can be found in reference 6. The SUGAR TBW wind-tunnel model is a 15 percent semispan side-wall mounted model. The model includes main and jury struts, pylon and annular nacelle, wing and fuselage. The scaled fuselage length was $18.8 \mathrm{ft}$, but it was shortened to 13.4 $\mathrm{ft}$ to reduce weight and potential torsional dynamics with the turntable mount. The mean aerodynamic chord is 16.5 inches. The model wing span to the center line is $12.75 \mathrm{ft}$ (about 75 percent of the tunnel width) with an additional 2.25 inches added to the half fuselage, the approximate wind-tunnel boundary layer displacement thickness.

The wing, strut and jury use a spar-pod design where the scaled stiffnesses ( $E I$ and $G J$ distributions) are designed into the flanged aluminum spar, and the aerodynamic shape is provided by discrete graphite epoxy fairings, or pods, mounted to the spars. The nacelle and pylon are not structurally scaled, but have the correct mass and inertia. The fuselage consists of an aluminum internal structure with fiberglass skin panels. Lead weights are attached to the wing spar in several locations so the wing has the proper scaled mass. The model is aeroelastically scaled for testing in heavy gas, which results in a heavier model, easier to build, with lower elastic mode frequencies minimizing actuator bandwidth requirements. Instrumentation for data aquisition included 11 strain gauges and 21 accelerometers. The model was supported by a turntable as shown in Figure 1, allowing the model angle-of-attack (AoA) to be varied between -3 and +5 degrees.

\section{Overview of flutter and LCO data}

For flutter testing, the goal is to establish the test conditions of flutter or limit cycle oscillation (LCO) onset. Here, the specification of these conditions is limited to Mach number and dynamic pressure. Operationally at the TDT, Mach number and dynamic pressure are not independent of each other and vary in unison with changes in the RPM of the TDT main drive motor for the fan blades at any given tunnel total pressure. Mach number and dynamic pressure vary along lines parallel to the the total pressure (h) lines as the main drive RPM increases. All SUGAR TBW experimental data under analysis in this paper was acquired in this way. It was acquired in heavy gas with a tunnel total pressure varying between approximately 250 and $450 \mathrm{psf}$.

Typical flutter testing in the TDT relies on naturally occurring tunnel turbulence to perturb the model. Mach number and dynamic pressure are gradually increased along each h-line until a flutter point is observed. Time history data are generally acquired along each h-line up to and including the flutter point. The determination of flutter is made visually by the test engineer from digital strip chart observations, modal frequency coallescence or other visual assessments. Once a flutter point is observed, Mach number and dynamic pressure are reduced to stabilize the model by gradually reducing main drive RPM or by opening the tunnel by-pass valves if warranted by the severity of the instability. Repeating this process over multiple h-lines allows the test engineers to define the flutter/LCO onset boundary. There is a typical $\Delta \mathrm{h}$ used in passing from one $\mathrm{h}$-line to the next. For this reason, at any given Mach number, the test points will likely be somewhat discontinuous as a function of dynamic pressure.

During the initial phases of testing, test engineers are more prone to trigger the by-pass valves at the first sign of an instability. As a test progresses, the test team becomes more familiar with both the aeroelastic response characteristics of the model and the effectiveness of the by-pass valves. For the SUGAR TBW model, points that were initially identified as flutter had very shallow crossings into undamping, and later determined to be LCO or intermittent LCO.

Testing of the TBW wind-tunnel model took place intermittently over the span of several months (December 2013 April 2014). Within this testing timeframe, a holiday break temporarily halted testing. There was an unplanned model change that occured during the holiday break. To make clear the key difference in data sets, data acquired before the holiday break will be called original-model data, data acquired after the holiday break will be called modified-model data. Thus, original model and modified-model GVT data were acquired. The Boeing Company generated finite element models based on GVT-acquired data. FEM v.19 was developed based on original-model GVT data and FEM v.20 was developed based on modified-model GVT data. A modified-model GVT revealed a shift in modal frequencies compared with the original model, and it was determined that there was not enough clearance between the strut root joint and the fairing. This determination was tested by looking at GVT results with and without a wedge inserted in a cut-out between the fairing and the inboard strut attachment. A comparison of original-model and modified-model GVT data and FEM v.19 and v.20 frequencies along with modal descriptions is given in Table 1. The differences in modified-model GVT data compared to the original model GVT data stem from an inadvertent configuration change due to the a fouling issue at the root of the strut. Further discussion of the fouling issue and the inadvertent structural configuration change can be found in reference 1 . This modification in the model caused significant changes to the model response, as will be discussed later.

Several hundred usable wind-tunnel test points were acquired in both original and modified-model testing. Most of 
the flutter testing for the SUGAR TBW test was conducted at angles of attack of $-3,-1,1$, and 3 degrees. Flutter/LCO onset boundaries were found to vary with AoA. These data are presented in detail in reference 1 . This AoA dependence was also noted in the analytical study described in reference 7.

The SUGAR TBW model exhibited LCO above an onset dynamic pressure. Hard flutter occured within a well defined region. A small subset of the flutter/LCO data for the SUGAR TBW model at -1 and +1 degrees are shown in Figure 2a and Figure 2b, respectively. These figures were created soon after test completion. The mechanism that drove the onset of LCO as well as hard flutter was a coalescence of the $2^{\text {nd }}$ out-of-plane bending and $1^{\text {st }}$ torsion modes at a frequency near $10 \mathrm{~Hz}$. In post-test data analysis, flutter/LCO onset was identified by a coalescence to a well defined single power spectral density (PSD) peak at around $10 \mathrm{~Hz}$. The assessment of stability versus weak or strong LCO was made based on test observations, examination of the time histories (e.g., LCO amplitude) and PSDs of the acquired data. The red symbols represent flutter or strong LCO data points, the blue symbols represent weak LCO points, and the open symbols represent stable points. A few data points where flutter suppression control laws were opened to assess stability are included on this plot. This approach was helpful in establishing part of the backside onset boundary and for filling in flutter points within the unstable region. At +1 degrees, test engineers reported that the model exhibited sustained torsional response at Mach numbers near 0.76. It should be noted that the SUGAR TBW wind-tunnel test was recently completed when Figures $2 \mathrm{a}$ and $2 \mathrm{~b}$ were made, and the labels weak and strong LCO were preliminary.

\section{Analysis of the LCO data}

Additional analysis of the LCO data was desireable so that a more accurate mapping of the LCO magnitudes could be developed. The data analysis began with a careful inspection of the accelerometer time histories. Of particular interest were the transverse (z direction) acceleration at the forward wing-tip station (which indicates participation of bending modes) and the engine nacelle (which indicates participation of the torsion modes). Figure 3 shows the locations of the two accelerometers. Data beyond by-pass valve openings were eliminated from consideration. Likewise, data taken while the flutter suppression system was operating were discarded. Variability in the Mach number, dynamic pressure and dynamic response of the two accelerometer time histories were then used to indicate where breaks between samples should be placed.

Figure 4 illustrates the variability in the dynamic response. The Mach number varies up to a half a percent over the usable portion of the record, that is, before the tunnel by-pass valves were opened. The wing-tip forward acceleration shows a much greater variability with peak-to-peak acceleration levels changing by over a factor of two. As also noted by Edwards regarding a similar test, ${ }^{5}$ when a model is near flutter onset, small changes in ambient flow conditions can cause large changes in the dynamics. Figure 5 illustrates the variability of the wing-tip acceleration over the course of a test point. The data samples selected from this test point are shown.

Another illustration of test data samples is shown in Figure 6. At this test point, the flutter suppression controller was cycled on and off. When the controller is off, valuable open loop flutter/LCO data can be extracted. An analysis of data samples 1 and 2 in that figure has been performed. For all data time histories, the rate is a constant 500 samples per second. Each sample shown represents a non-overlapping rectangular window. The flat-top window function was used to reduce scalloping loss. ${ }^{8,9}$ Before analyzing the data, the algorithm was tested for accuracy. The error in the amplitude of a unit sinusoid for various window sizes (number of data points) and frequencies was of the order of 0.001-0.01 dB.

Returning to the data samples in Figure 6, the amplitude of the approximately $10 \mathrm{~Hz} \mathrm{LCO}$ mode has been measured from the spectral analysis of the time history. An example of the spectral data from a data sample of the forward wingtip acceleration is shown in Figure 7. From the fast-Fourier transform (FFT) data, the amplitude of the $9.8 \mathrm{~Hz} \mathrm{LCO}$ is $4.5 \mathrm{~g}$ for data sample 1 and $4.1 \mathrm{~g}$ for data sample 2 .

Table 2 indicates the number of samples at each AoA. The product of all the samples compiled is a catalogue of the LCO amplitudes and frequencies from the forward wing-tip and nacelle accelerometers. In all cases, the desired LCO amplitude was taken to be the largest peak spectral response in the 6-14 Hz range. Figure 8 shows histograms of the frequencies of all samples for 0-3, 3-5, 5-8, 8-15 g-levels separated by AoA. At all angles-of-attack, the FFT peaks were distributed over most of the frequency range for $0-3 \mathrm{~g}$. Above $3 \mathrm{~g}$, all fall within an 8-11 $\mathrm{Hz}$ range. Since there is a $3 \mathrm{~g}$ lower bound in LCO amplitudes retained in the current study, this confirms that a search in the 6-14 Hz range acquires all the FFT peaks that are above that cutoff. In passing, note that the samples in the 0-3 g-levels are to some degree influenced by broad-spectrum tunnel turbulence, however, it is interesting that there is a discernably larger content in the 6-7 Hz than the 13-14 Hz range.

In order to create plots of contours describing the LCO amplitudes, the data at each AoA is divided into bins over 
successive Mach number ranges. Figures 9-11 illustrate the data divided in this manner for several Mach number ranges at an AoA of -1 degree. It is clear that at a given Mach and dynamic pressure, there are many LCO amplitude values distributed up to a maximum value. This is due to the variability of the data discussed earlier. The maximum value is used to generate the LCO amplitude contour plot at a given Mach number and dynamic pressure.

An enveloping curve is created for each Mach number bin that encloses the largest LCO amplitude. Examples of the enveloping curves are the red lines in Figures 9-11. The attempt has been made to follow as closely as possible the data rise up to the maximum amplitude value. As discussed previously, LCO amplitudes below $3 \mathrm{~g}$ are ignored since broad band excitation due to tunnel turbulence clearly becomes more influencial below that value. Finally, note that there are some instances where, after a peak LCO amplitude at a lower dynamic pressure, the LCO amplitude appears to drop off at higher dynamic pressures. See for instance Figure 9. The drop off may either be due to a lack of data in that Mach/dynamic pressure range or it could be because of important physics, e.g., a flutter hump mode. Because of the uncertainty in the reason for the drop off in amplitude, the enveloping curve is not carried out to higher dynamic pressures than the maximum LCO amplitude.

Enveloping curves such as these have been created for both the wing-tip and nacelle accelerometers at all AoAs. The envelop curves were then rearranged into the contour plots shown in Figures 12-15 and Figures 19-23. Because of the changes that occured between the original-model GVT and the modified-model GVT, modified-model data have been plotted separately. But, because of the sparsity of original-model data, only 'all data' and 'modified-model data' are plotted. It will be noted that there are intermittent breaks in the contours of LCO amplitude. This can be seen in all the plots however, the breaks in contours in Figure 13 can be compared with Figures 9a-11a to explain why this occurred. In Figures 9a-11a, in the Mach number range 0.75-0.77, the LCO amplitude of $10 \mathrm{~g}$ is higher than the amplitude at either lower or higher Mach numbers. Figure 13, therefore, indicates a $10 \mathrm{~g} \mathrm{LCO}$ at only Mach 0.76. Such isolated or broken contour segments may be indicative of an isolated physical phenomena or a hump mode.

Regarding general differences between the 'all data' and 'modified-model' data plots, the forward wing-tip accelerometer data strongly contrast between the two data sets at only AoAs of -1 and +3 degrees. At AoA of -1 degree, 9-10 g responses do not appear in the 'modified-model' data and there are shape differences in the contours, particularly in the Mach 0.76-0.81 range. The rise in LCO amplitude is clearly not as rapid in the 'modified-model' data plot. At AoA of +3 degrees, there is a continuation of the 5 and $6 \mathrm{~g}$ contours below Mach 0.78 in the 'all data' plot. Above Mach 0.80, the 'modified-model data' LCO amplitude rises somewhat more rapidly. For the nacelle accelerometer (data plots in Figures 19-23), there is a discernable contrast at all AoAs. This may be an indication that the $1^{\text {st }}$ wing bending/torsion mode at $11 \mathrm{~Hz}$ is more sensitive to model changes than the 8-9 $\mathrm{Hz} 2^{\text {nd }}$ out-of-plane wing bending mode.

The line between stable LCO and hard flutter is also shown in each of the plots. That line is the V-shape shown in many of the figures or a downward slanted line in some. At AoA of +3 degree, it is a nearly vertical line near Mach 0.80 . The hard flutter lines are taken from Allen et al. ${ }^{3}$ The hard flutter line is the boundary of a Mach number/dynamic pressure region in which excessive model dynamics required immediate tunnel flow shut down. Where there is only one side of the V-shape, the upper Mach number boundary was not sufficiently explored to characterize it. It is clear that there was high, but manageable, model dynamics at all Mach numbers well before the hard flutter onset. Also, for all AoA, the wing-tip and nacelle experience a rapid rise in dynamics well before hard flutter onset. If the LCO onset can be defined as the dynamic pressure at which the amplitude rises sharply, a clear point of LCO onset can be observed at many Mach numbers.

What has often been termed a "flutter dip" or "flutter bucket" can be seen in the LCO onset at all angles of attack in the vicinity of Mach 0.78-0.81. For the present discussion, in order to distinguish the hard flutter from the LCO onset, the lowest dynamic pressure at which LCO onset occurs will be called the LCO bucket. The flutter bucket will be associated with the point of minimum dynamic pressure in the hard flutter onset. In either case, the bucket is associated with strong transonic compressibility effects and possibly strong viscous-inviscid interaction. Note that at AoAs of -3 degrees (Figure 12) and -1 degree (Figure 13), the wing-tip LCO bucket is well past the Mach range in which the flutter bucket occurs. However, as the angle-of-attack increases, the Mach number of the flutter bucket also increases. At AoAs of +1 degree (Figure 14) and especially at +3 degrees (Figure 15), the Mach number range of the flutter bucket has risen sufficiently that it matches well with the LCO bucket. It has been pointed out elsewhere that the flutter bucket rises in dynamic pressure with increase in angle-of-attack. ${ }^{3}$ This rise is also seen in the LCO onset.

With the exception of an AoA of -3 degrees, the wing-tip LCO onset experiences a rapid rise in dynamic pressure around Mach 0.80-0.81. At AoA of -3 degrees (Figure 12), the rise occurs earlier, around Mach 0.77. Also, while the $3 \mathrm{~g}$ LCO contour rises slightly from AoAs of -1 to +1 degrees, the $5 \mathrm{~g}$ and higher LCO contours rise much faster between Mach 0.72 and 0.77. At an AoA of +1 degree (Figure 14), the rapid rise in LCO amplitude hugs the hard flutter onset closely. The difference in the regions of large LCO response in Figures 13-14 mirrors the differences 
between AoAs of -1 and +1 degrees seen in the stable/weak LCO to flutter/strong LCO transitions seen in Figure 2. At AoA of +3 degrees in Figure 15, there appears to be very little model dynamics at any dynamic pressure until Mach 0.77. At +3 degrees in the Mach 0.77-0.80 range, the forward wing-tip LCO 5-6 g contours (Figure 15) oscillate with increasing Mach number. This feature is explained by Figures 16-18. Following the $6 \mathrm{~g}$ level, the dynamic pressure is at $86 \mathrm{psf}$ in the Mach 0.77-78 range (Figure 16a), then rises to $96 \mathrm{psf}$ in the Mach 0.78-0.80 range (Figure 17a) and drops again to $84 \mathrm{psf}$ in the Mach 0.80-0.81 range ( (Figure 18a).

The overall rise in dynamic pressure with increasing angle-of-attack of the wing-tip LCO onset is seen in nacelle LCO onset. However, the nacelle LCO bucket is not as clearly defined. In fact, only at -1 and +3 degrees in the plots of 'all data' are there well defined nacelle LCO buckets. At AoAs of -3 and +1 degrees, the nacelle LCO onset line is rather difficult to characterize. At AoA of -3 degrees, the contours of LCO amplitude do not follow the hard flutter onset lines at all. This would indicate that nacelle acceleration, and thus, wing torsion is not strongly correlated with hard flutter onset at that angle-of-attack.

The nacelle LCO amplitude map at +1 degree is very interesting (Figure 21). The rise to high amplitude nacelle LCO amplitude (wing torsion) follows the hard flutter onset quite well. There is also much higher nacelle dynamics at this AoA than at any other. Peak LCO amplitudes reach $1.6 \mathrm{~g}$. Furthermore, there are high nacelle acceleration levels at Mach 0.75-0.76 in the 90-110 psf range. This corresponds very well with the observations made by test engineers, and referred to earlier. The report had been made that there was a region of high torsional dynamics preceeding the hard flutter onset. ${ }^{1}$ This is precisely the behavior shown in Figure 21. What was not reported, but is shown here, is that the high torsional dynamics continues through the hard flutter region. In fact, the highest torsional dynamics are shown well into hard flutter.

Finally, Figure 23 compares the MSC.Nastran generated flutter results with the current LCO contours at an AoA of -1 degree. Figure 23a presents a comparison of the FEM v.19 and all LCO data while Figure 23b compares FEM v. 20 with the modified-model data. The simulation results are taken from reference 10. The linear MSC.Nastran (SOL 145) flutter analysis uses the $p-k$ method (with no looping). A matched set of densities and velocities are calculated based on R134a as the test medium. Steady aerodynamic corrections based on CFD results are utilized to improve the fidelity of the aerodynamics used in the simulations. The MSC.Nastran flutter onset compares remarkably well with the line marking the rapid rise in LCO magnitude.

\section{Concluding remarks}

The paper presents a detailed analysis of dynamic aeroelastic data from The Boeing Company SUGAR TBW model test in the Transonic Dynamics Tunnel. The wing-tip and engine nacelle accelerometer time histories provide a window into the dynamics of the vehicle. The accelerometer data from hundreds of test points were separated into small samples in which ambient conditions as well as dynamic response of the vehicle can be considered relatively time invariant. Spectral analysis provides the amplitude of the approximately $10 \mathrm{~Hz}$ flutter/LCO dynamics. The SUGAR TBW wind-tunnel flutter model experienced both classical flutter as well as LCO phenomena. A mapping of the various levels of dynamics short of hard flutter add insight into the nature of the flow conditions encountered by the model. This analysis confirms the general trends with increasing AoA that have been observed in previous publications. A mapping of LCO contours also provides a much better picture of onset of vehicle dynamics than does either a mapping of hard flutter onset or display of individual LCO points. An LCO bucket is revealed which, at AoAs of -3 and -1 degrees, does not correspond exactly with the previously published hard flutter bucket. The rapid rise in LCO amplitude, which can be termed LCO onset, also corresponds very well with the linear flutter onset simulations for this model. The simulation results are a better match with the LCO onset than with the hard flutter onset. The better match is consistent for both the original and modified-model finite element models. It can be concluded from these results that the rapid rise in LCO magnitude is a better indicator of flutter onset than the hard flutter onset. This suggests that the LCO onset, rather than hard flutter onset, may be a better estimator of the goodness of the simulations.

\section{References}

\footnotetext{
${ }^{1}$ Bradley, M. K., Droney, C. K., and Allen, T. J., "Subsonic Ultra Green Aircraft Research: Truss Braced Wing Aeroelastic Test Report," Contractor report, The Boeing Company, June 2014.

${ }^{2}$ Bartels, R. E., Scott, R. C., Funk, C. J., Allen, T. J., and Sexton, B. W., "Computed and Experimental Flutter/LCO Onset for the Boeing Truss-Braced Wing Wind-Tunnel Model," 32st AIAA Applied Aerodynamics Conference, No. AIAA-2014-9999, Atlanta, GA, June 2014.

${ }^{3}$ Allen, T. J., Sexton, B., and Scott, M. J., "SUGAR Truss Braced Wing Full Scale Aeroelastic Analysis and Dynamically Scaled Wind Tunnel Model Development," 56th AIAA/ASCE/AHS/ASC Structures, Structural Dynamics, and Materials Conference, No. AIAA 2015-1171, 2015.

${ }^{4}$ Scott, R. C., Allen, T. J., Castelluccio, M., Sexton, B., Claggett, S., Dykman, J. R., Funk, C. J., Coulson, D., and Bartels, R. E., "Aeroser-
} 
voelastic Wind-Tunnel Test of the SUGAR Truss-Braced Wing Wind-Tunnel Model," 56th AIAA/ASCE/AHS/ASC Structures, Structural Dynamics, and Materials Conference, No. AIAA 2015-1172, 2015.

${ }^{5}$ Edwards, J. W., Spain, C. V., Keller, D. F., Moses, R. W., and Schuster, D. M., "Transport Wing Flutter Model Transonic Limit Cycle Oscillation Test," Journal of Aircraft, Vol. 46, No. 4, July-August 2009, pp. 1104-1113.

${ }^{6}$ Bradley, M. K. and Droney, C. K., "Subsonic Ultra Green Aircraft Research: Truss Braced Wing Design Exploration," Contractor report, The Boeing Company, June 2014.

${ }^{7}$ Coggin, J. M., Kapania, R. K., Zhao, W., Schetz, J. A., Hodigere-Siddaramaiah, V., Allen, T. J., and Sexton, B. W., "Nonlinear Aeroelastic Analysis of a Truss Braced Wing Aircraft," 55th AIAA/ASMe/ASCE/AHS/SC Structures, Structural Dynamics, and Materials Conference, No. AIAA-2014-0335, National Harbor, MD, Jan. 2014.

${ }^{8}$ Lyons, L., "Reducing FFT Scalloping Loss Errors Without Multiplication,” IEEE Signal Processing Magazine, March 2011, pp. 113-116.

${ }^{9}$ Mathworks, "Signal Processing Toolbox: flattopwin," http://www.mathworks.com/help/signal/ref/flattopwin.html, 2015.

${ }^{10}$ Bartels, R. E., Scott, R. C., Allen, T. J., and Sexton, B. W., "Aeroelastic Analysis of SUGAR Truss-BracedWing Wind-Tunnel Model Using FUN3D and a Nonlinear Structural Model," 56th AIAA/ASCE/ASME Structures, Structural Dynamics and Materials Conference, Kissimmee, FL, January 2015. 
Table 1. Original and modified-model modal data.

\begin{tabular}{cccccc}
\hline \hline Mode & $\begin{array}{c}\text { Original GVT } \\
(\mathrm{Hz})\end{array}$ & $\begin{array}{c}\text { FEM v.19 } \\
(\mathrm{Hz})\end{array}$ & $\begin{array}{c}\text { Modified-model GVT } \\
(\mathrm{Hz})\end{array}$ & $\begin{array}{c}\text { FEM v.20 } \\
(\mathrm{Hz})\end{array}$ & Description \\
\hline 1 & 5.20 & 5.12 & 5.08 & 5.04 & $1^{\text {st }}$ out-of-plane wing bending \\
3 & 9.08 & 9.17 & 8.43 & 8.44 & $2^{\text {nd }}$ out-of-plane wing bending \\
4 & 11.35 & 11.34 & 11.14 & 11.28 & $1^{\text {st }}$ wing/nacelle torsion \\
5 & 19.56 & 18.35 & 18.62 & 18.46 & $3^{\text {rd }}$ wing bending/nacelle torsion \\
7 & 28.44 & 27.44 & 27.57 & 27.13 & $4^{\text {th }}$ wing bending/nacelle torsion \\
& & & & \\
\hline \hline
\end{tabular}

Table 2. Number of data samples at each AoA.

\begin{tabular}{cc}
\hline \hline $\begin{array}{c}\text { AoA } \\
\text { (degrees) }\end{array}$ & No. of samples \\
\hline-3 & 1882 \\
-1 & 1179 \\
+1 & 1223 \\
+3 & 1408 \\
\end{tabular}




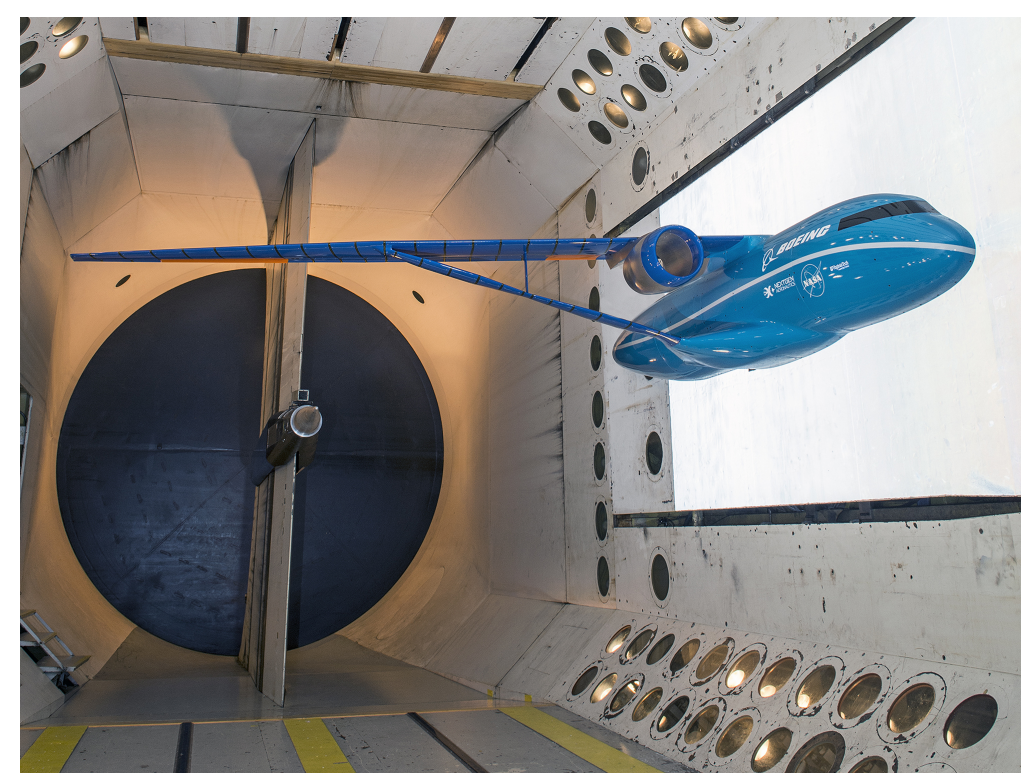

Figure 1. Photo of the SUGAR model in the Transonic Dynamics Tunnel. 


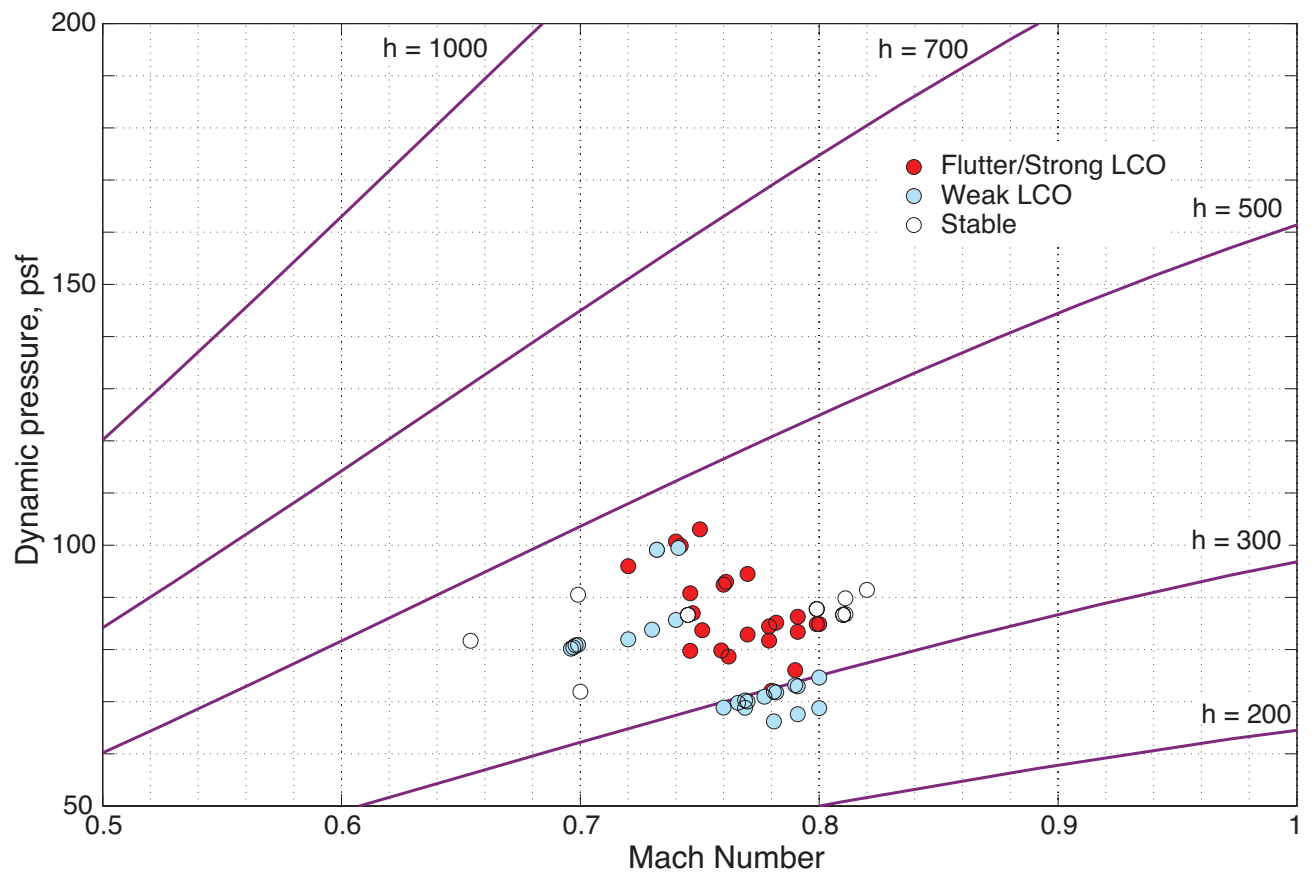

(a) $\mathrm{AoA}=-1.0$ degree

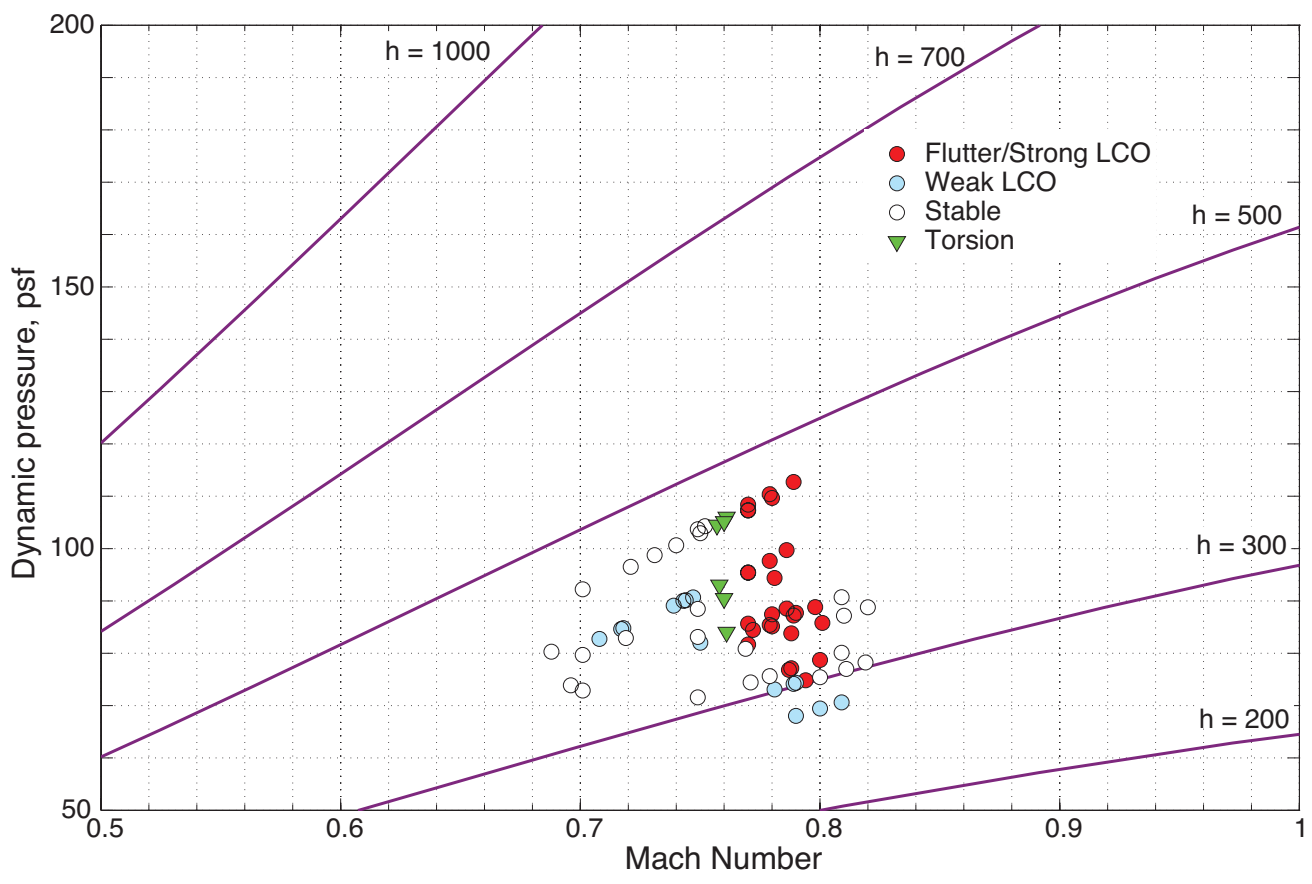

(b) $\mathrm{AoA}=+1.0$ degree

Figure 2. TDT experimental flutter/LCO points at two angles of attack (h given in psf). 


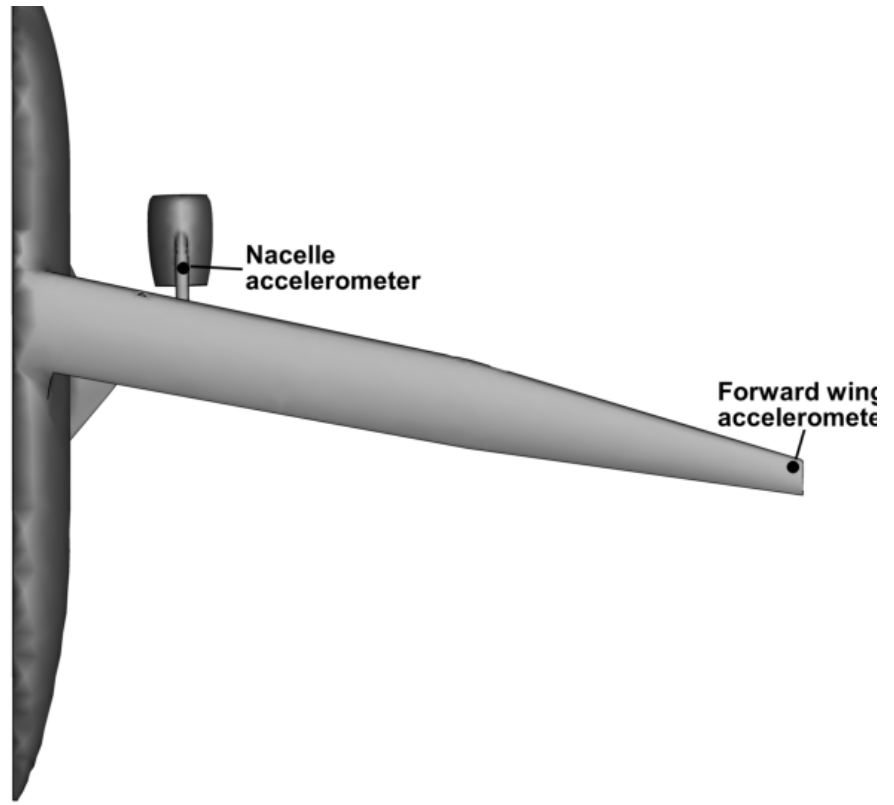

Figure 3. Locations of accelerometers used in the current study.

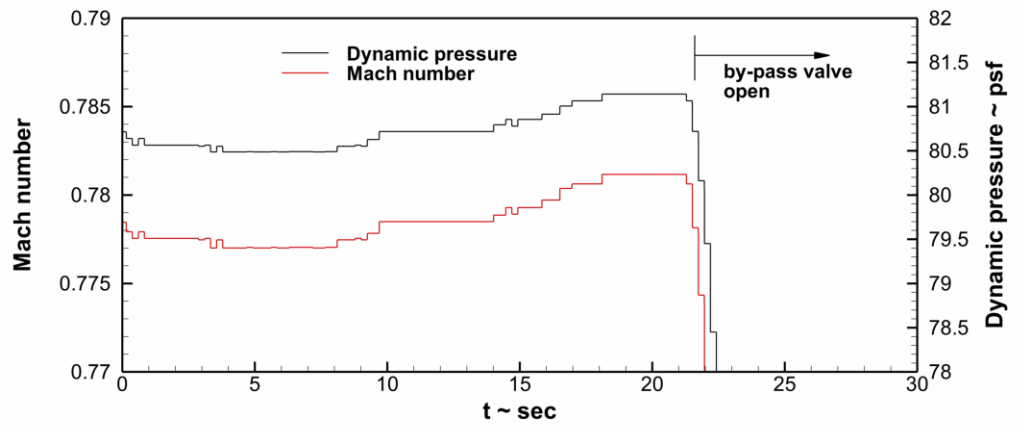

(a) Mach number and dynamic pressure

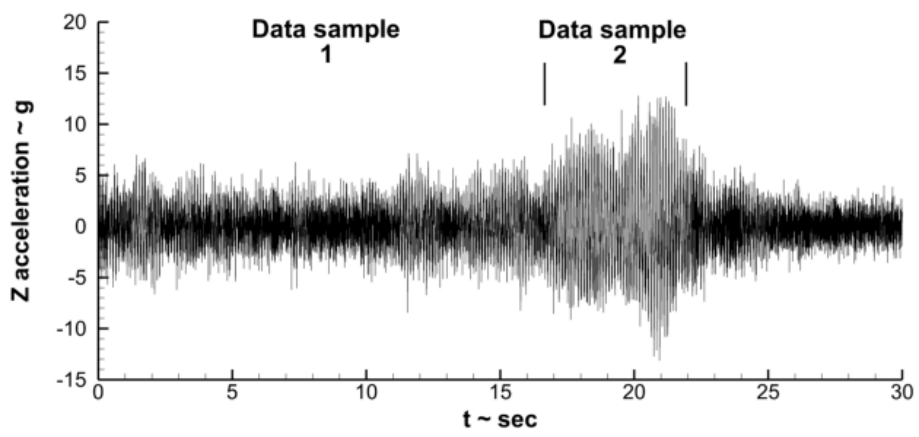

(b) Forward wing-tip acceleration

Figure 4. Illustration of test point requiring windowing to isolate time localized events. 


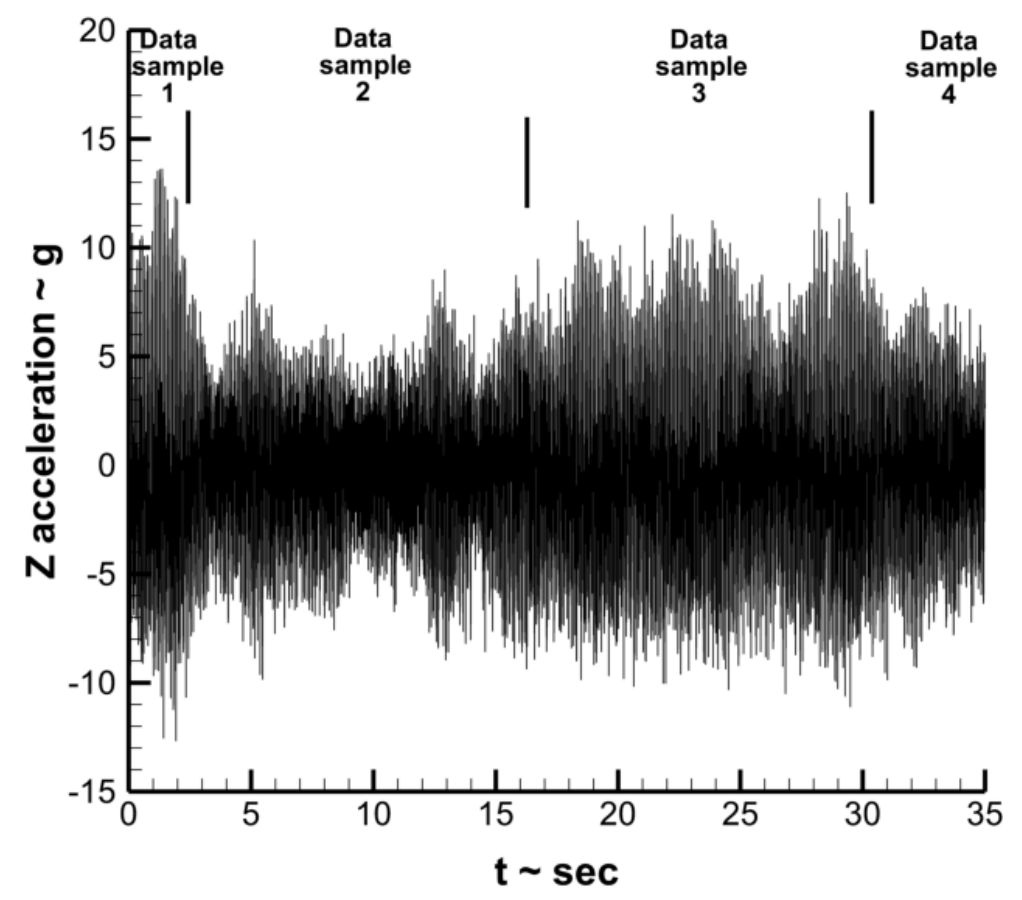

Figure 5. Time history variability of wing-tip acceleration for test point 2173.

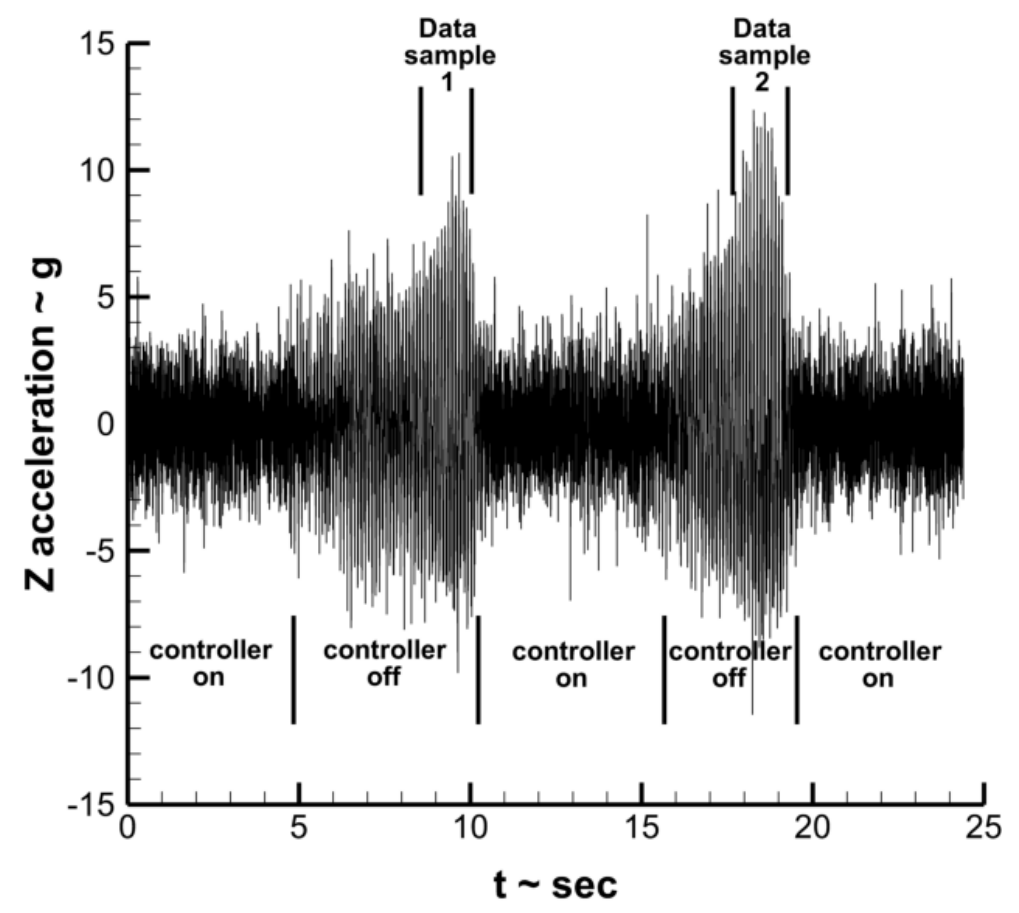

Figure 6. Time history of forward wing-tip acceleration for test point 3226. 


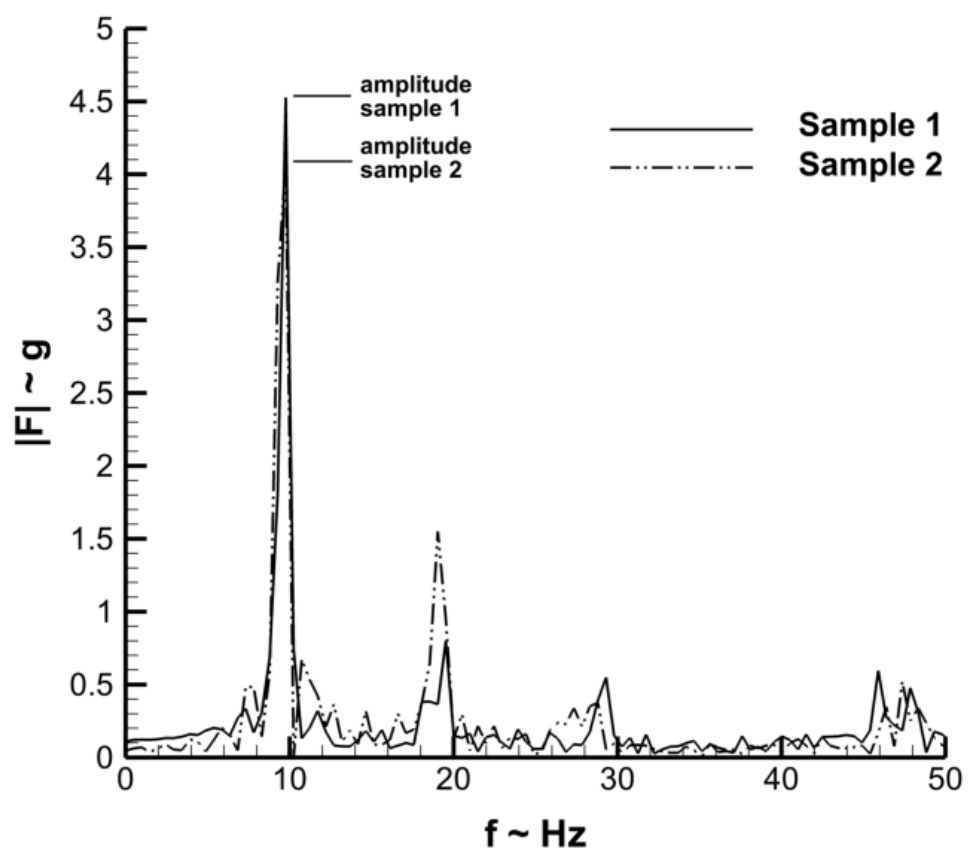

Figure 7. Magnitude of FFT of forward wing-tip acceleration for test point 3226. 


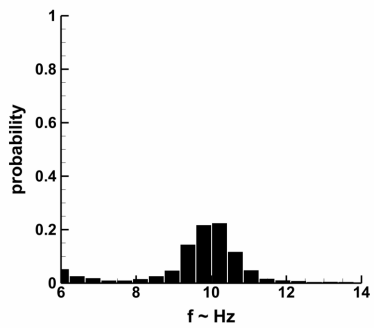

(a) $\mathrm{AoA}=-3$ degree, $0-3 \mathrm{~g}$

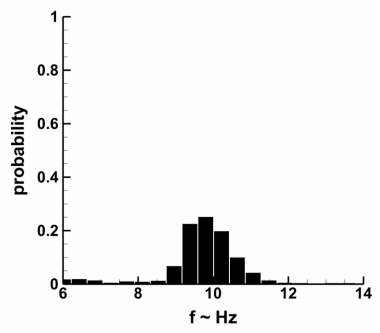

(e) $\mathrm{AoA}=-1$ degree, $0-3 \mathrm{~g}$

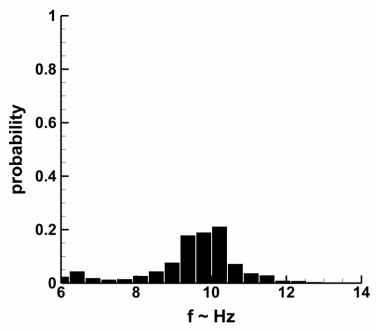

(i) $\mathrm{AoA}=+1$ degree, $0-3 \mathrm{~g}$

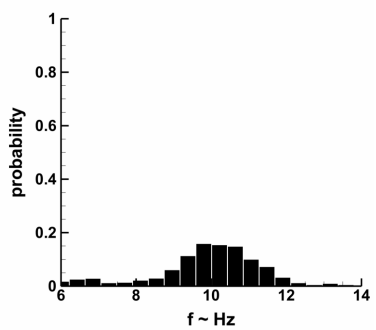

(m) AoA $=+3$ degree, 0-3 g

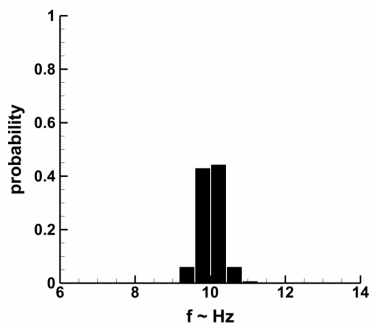

(b) $\mathrm{AoA}=-3$ degree, $3-5 \mathrm{~g}$

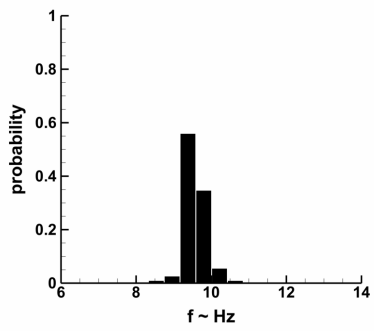

(f) $\mathrm{AoA}=-1$ degree, $3-5 \mathrm{~g}$

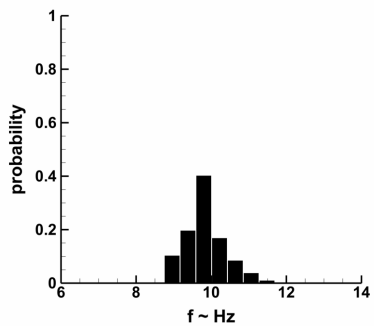

(j) AoA $=+1$ degree, $3-5 \mathrm{~g}$

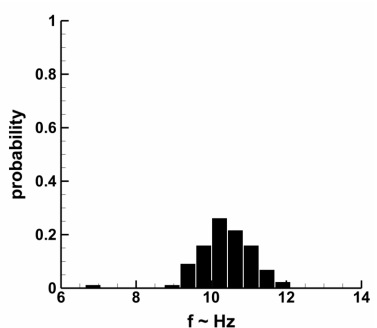

(n) $\mathrm{AoA}=+3$ degree, $3-5 \mathrm{~g}$

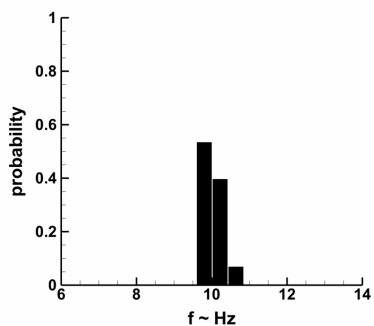

(c) $\mathrm{AoA}=-3$ degree, $5-8 \mathrm{~g}$

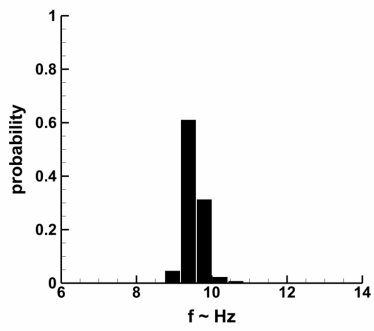

(g) $\mathrm{AoA}=-1$ degree, 5-8 g

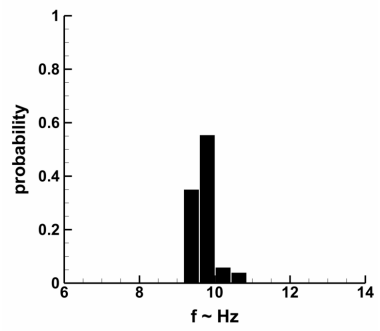

(k) AoA $=+1$ degree, 5-8 g

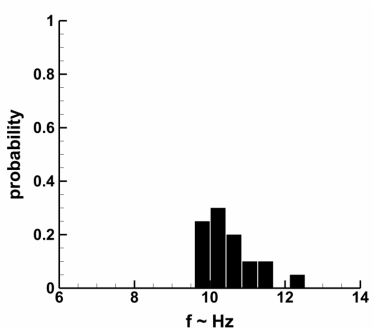

(o) AoA $=+3$ degree, 5-8 g

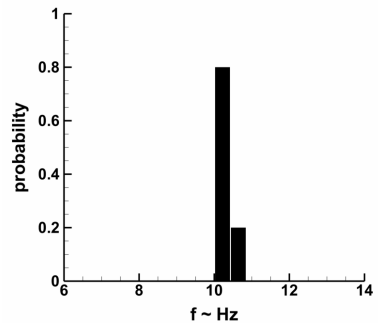

(d) $\mathrm{AoA}=-3$ degree, $8-15 \mathrm{~g}$

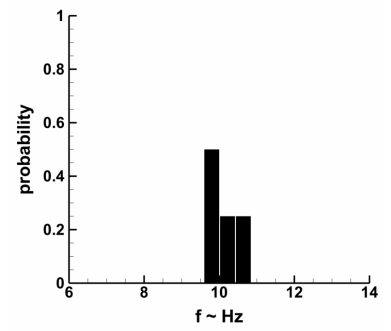

(h) $\mathrm{AoA}=-1$ degree, $8-15 \mathrm{~g}$

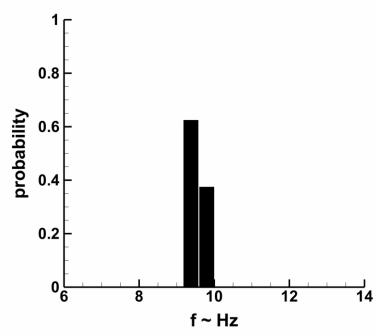

(1) $\mathrm{AoA}=+1$ degree, $8-15 \mathrm{~g}$

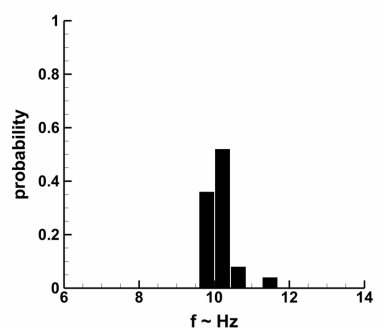

(p) AoA $=+3$ degree, $8-15 \mathrm{~g}$

Figure 8. Histograms of LCO frequency as a function of angle of attack and forward wing-tip g level. 


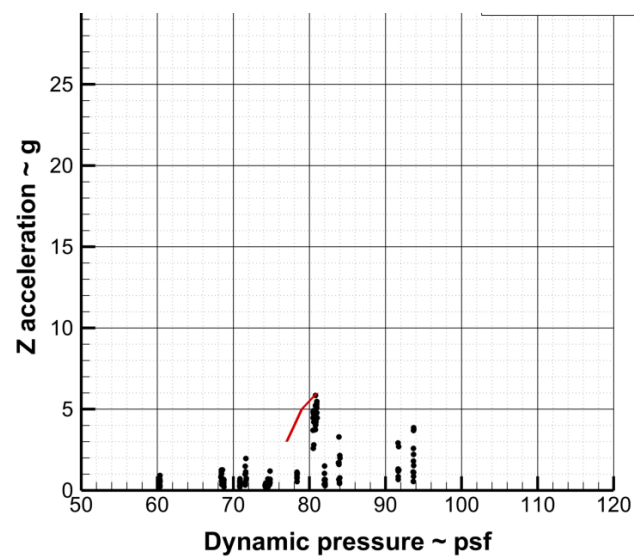

(a) all data

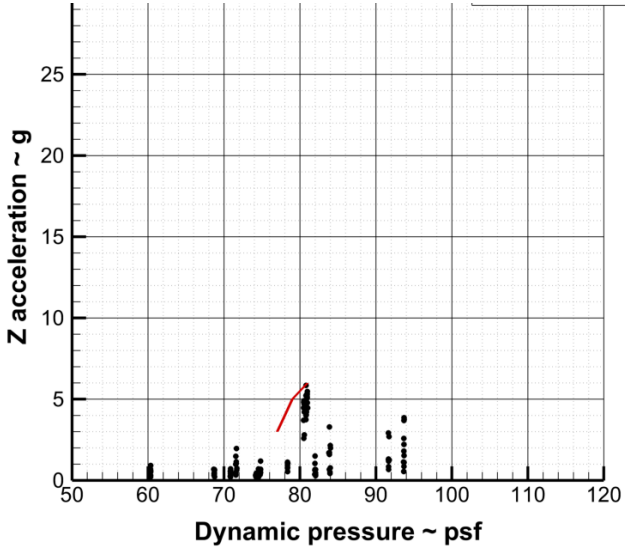

(b) modified-model data

Figure 9. LCO amplitudes, Mach 0.70-0.72, AoA = -1 degree (black symbols - wind-tunnel data, red line - envelope enclosing data).

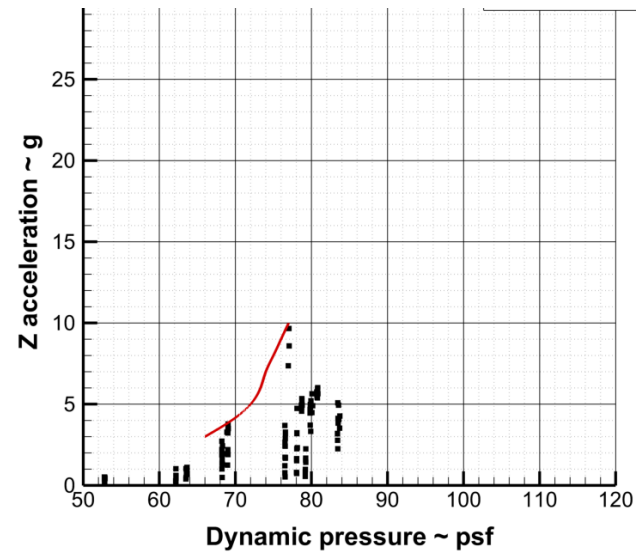

(a) all data

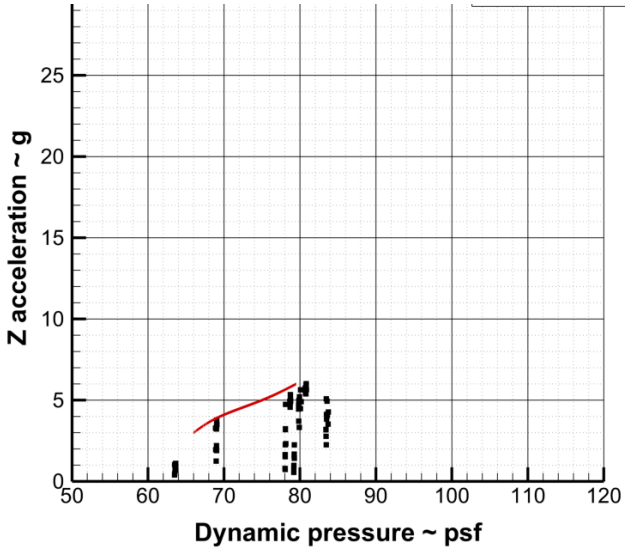

(b) modified-model data

Figure 10. LCO amplitudes, Mach 0.75-0.77, AoA = -1 degree (black symbols - wind-tunnel data, red line - envelope enclosing data).

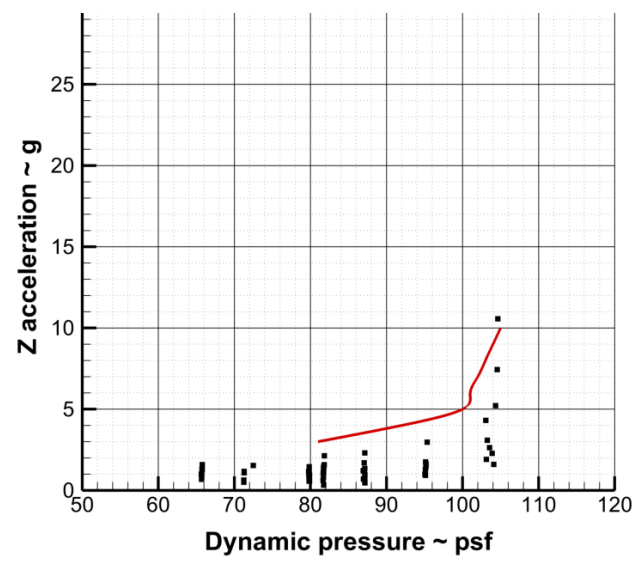

(a) all data

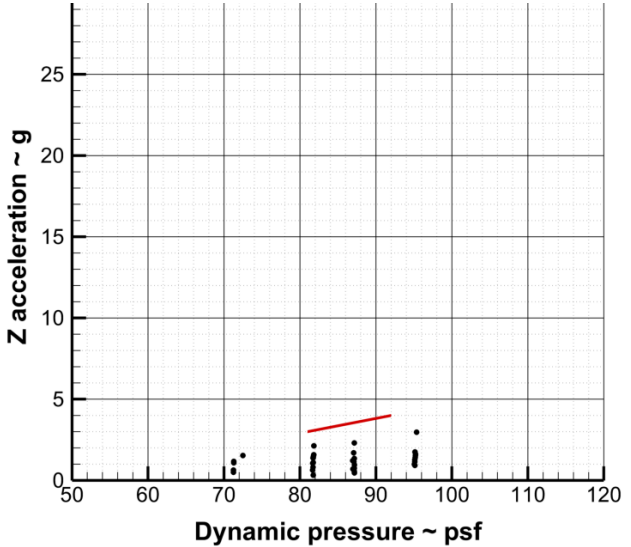

(b) modified-model data

Figure 11. LCO amplitudes, Mach 0.77-0.78, AoA = -1 degree (black symbols - wind-tunnel data, red line - envelope enclosing data). 


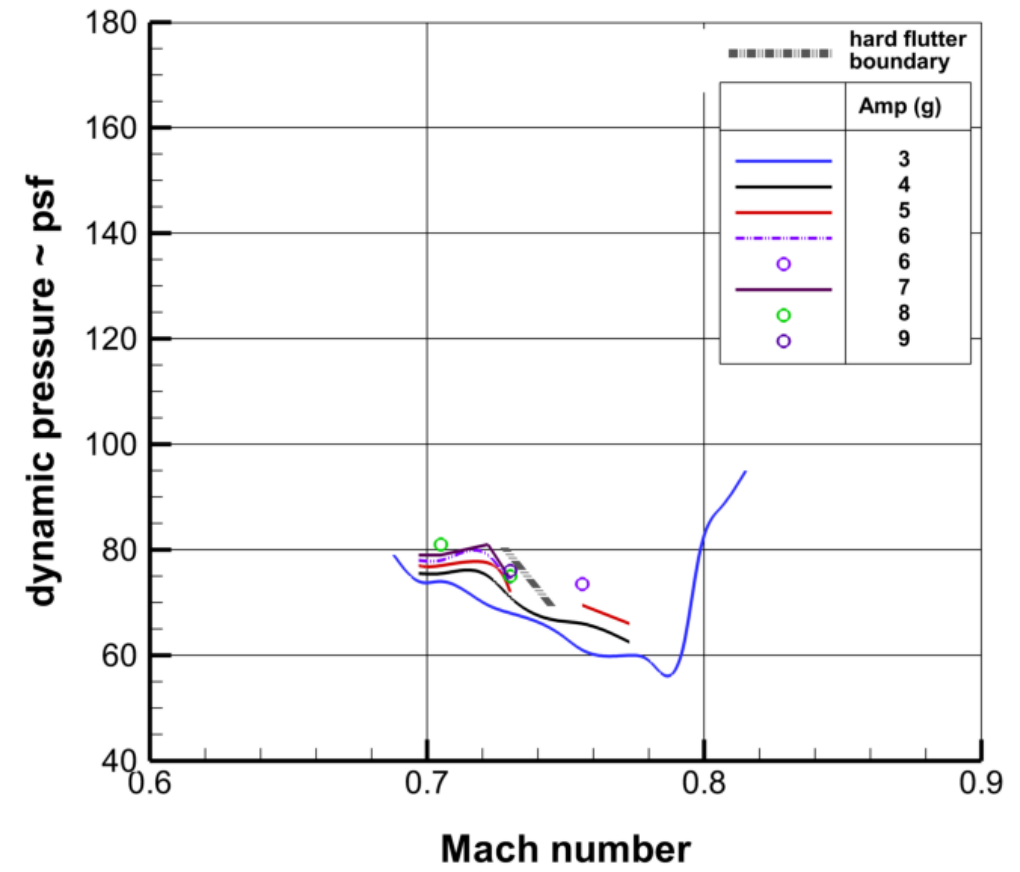

(a) all data

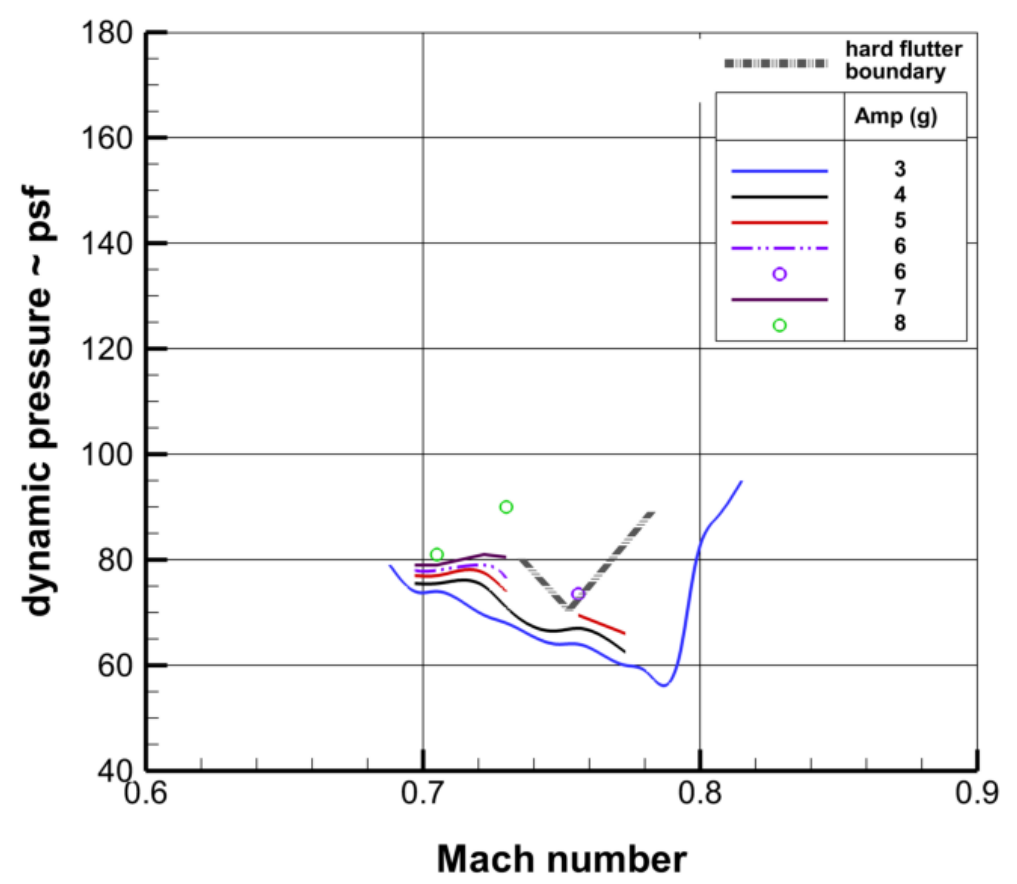

(b) modified-model data

Figure 12. Amplitudes of $10 \mathrm{~Hz}$ forward wing-tip z-acceleration, $\mathrm{AoA}=-\mathbf{3}$ degrees. 


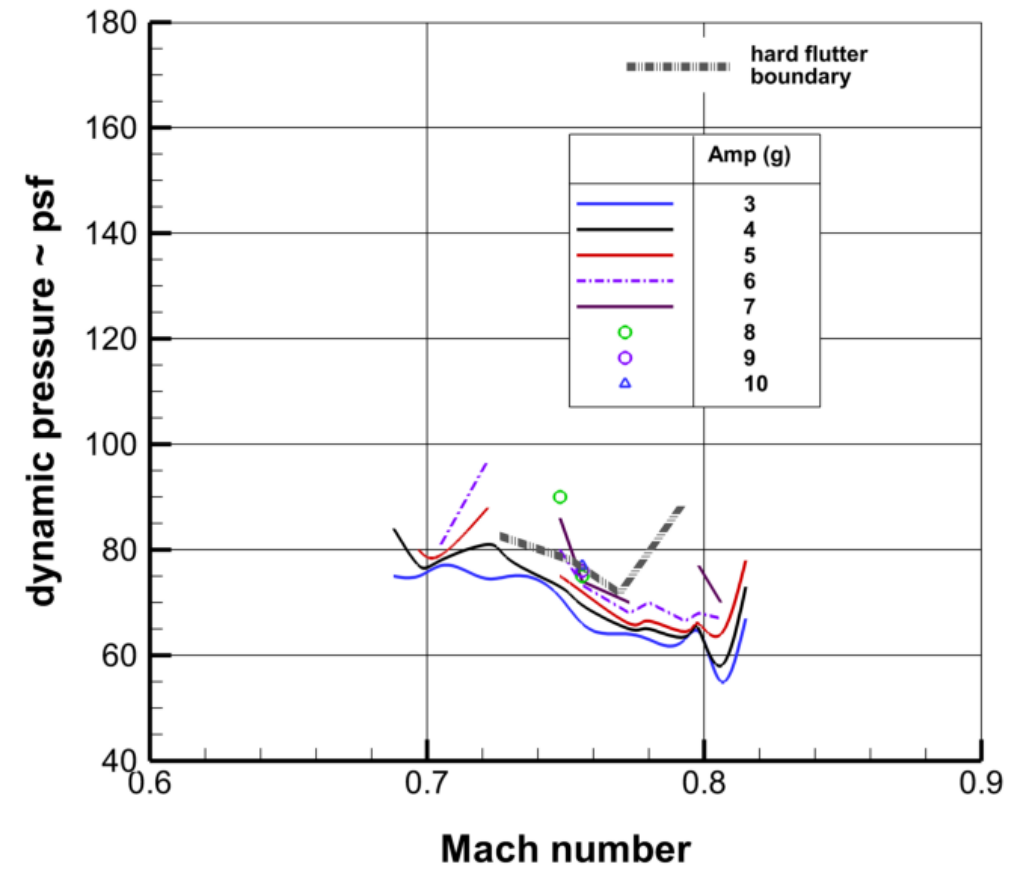

(a) all data

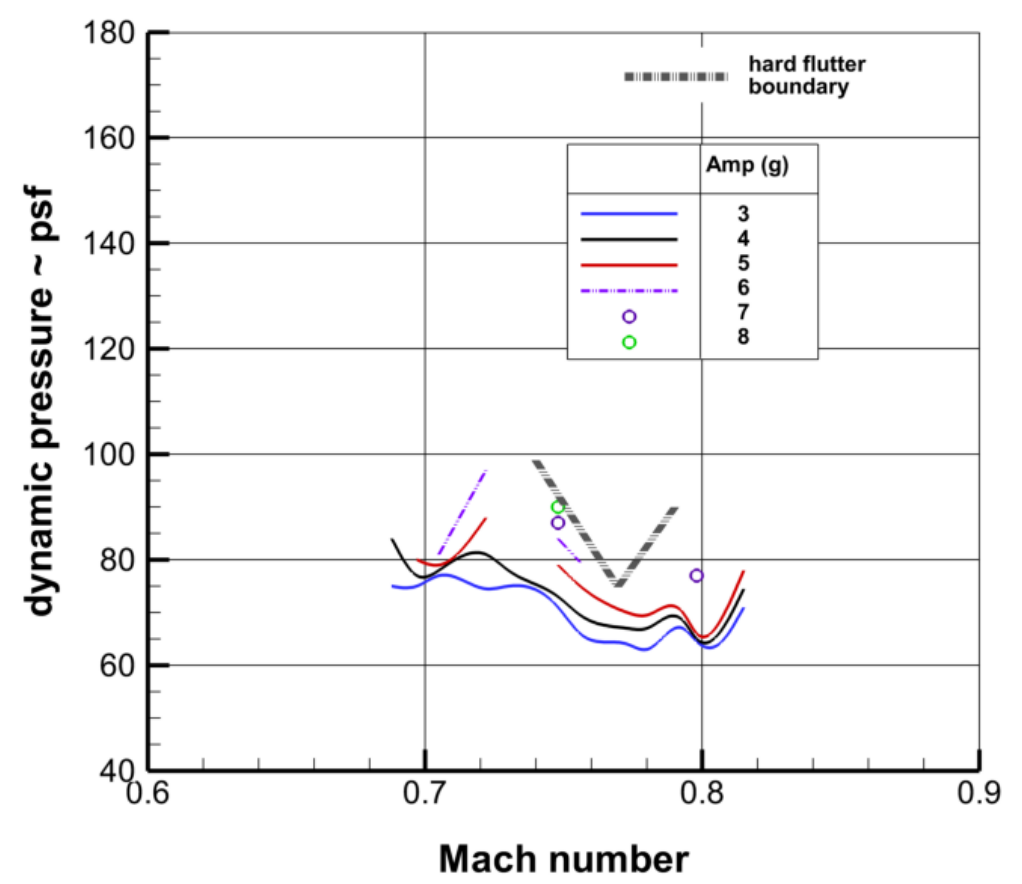

(b) modified-model data

Figure 13. Amplitudes of $10 \mathrm{~Hz}$ forward wing-tip z-acceleration, $\mathrm{AoA}=-1$ degree. 


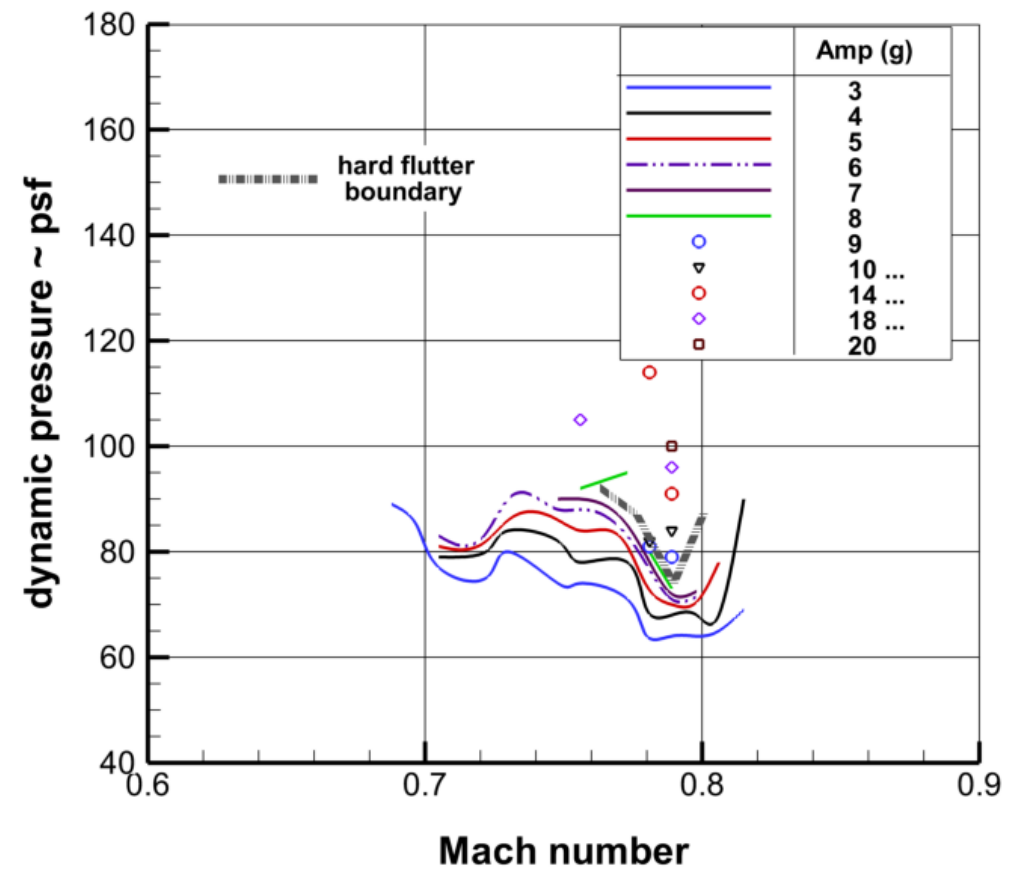

(a) all data

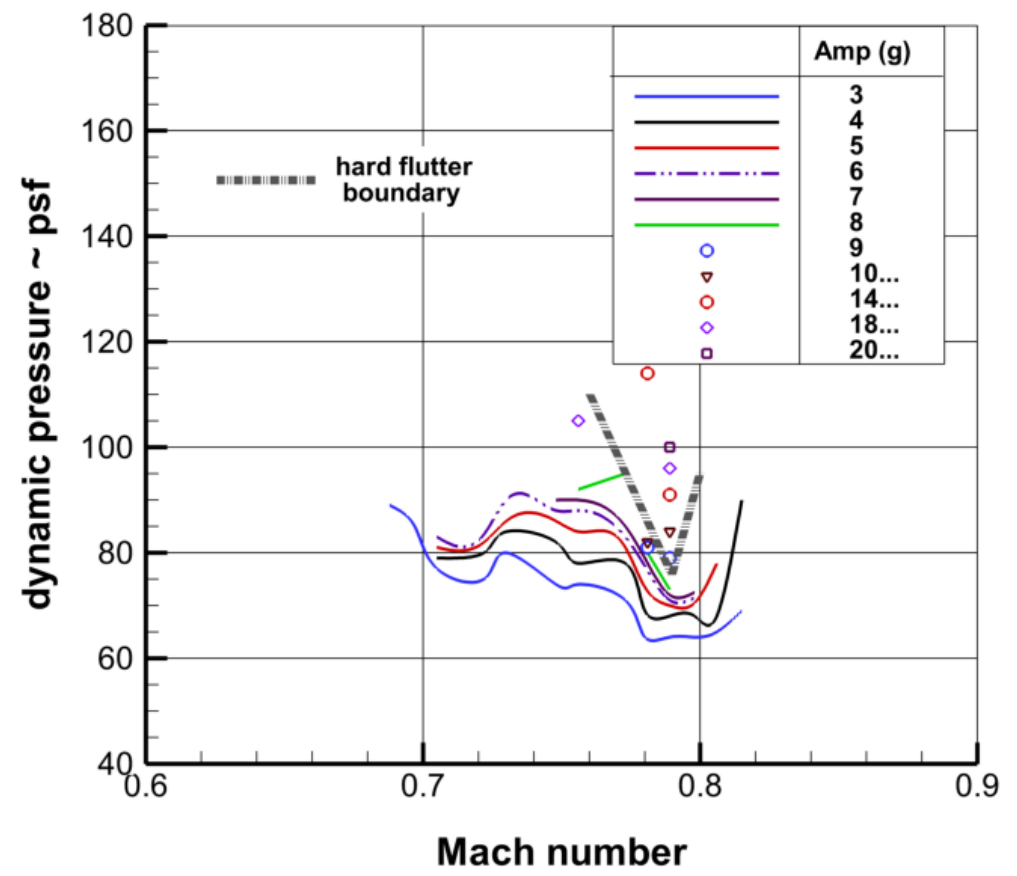

(b) modified-model data

Figure 14. Amplitudes of $10 \mathrm{~Hz}$ forward wing-tip z-acceleration, $\mathrm{AoA}=+1$ degree. 


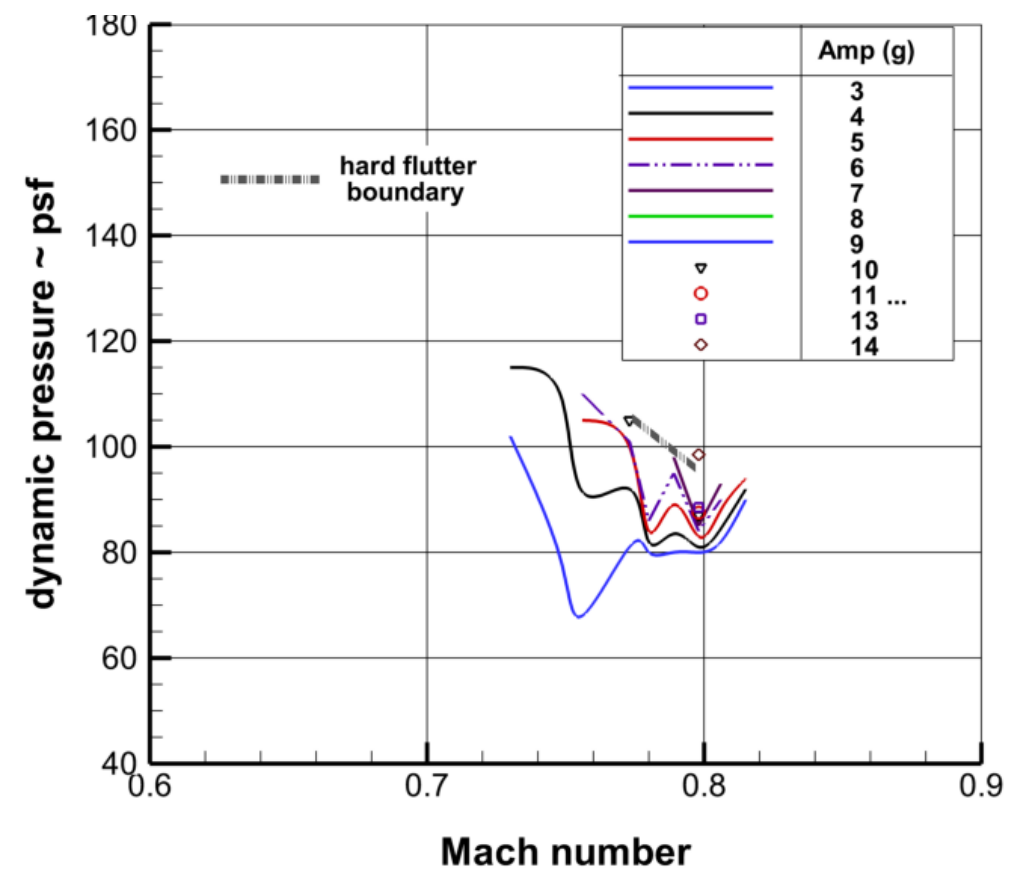

(a) all data

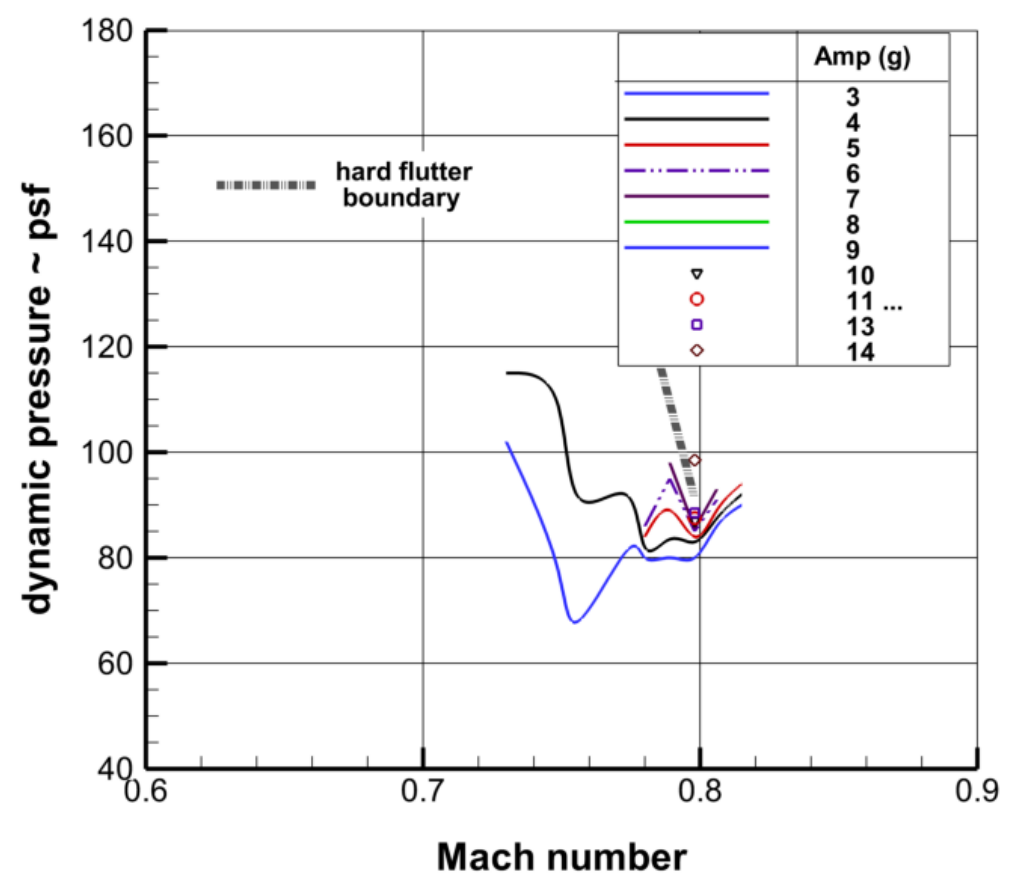

(b) modified-model data

Figure 15. Amplitudes of $10 \mathrm{~Hz}$ forward wing-tip z-acceleration, $\mathrm{AoA}=+3$ degrees. 


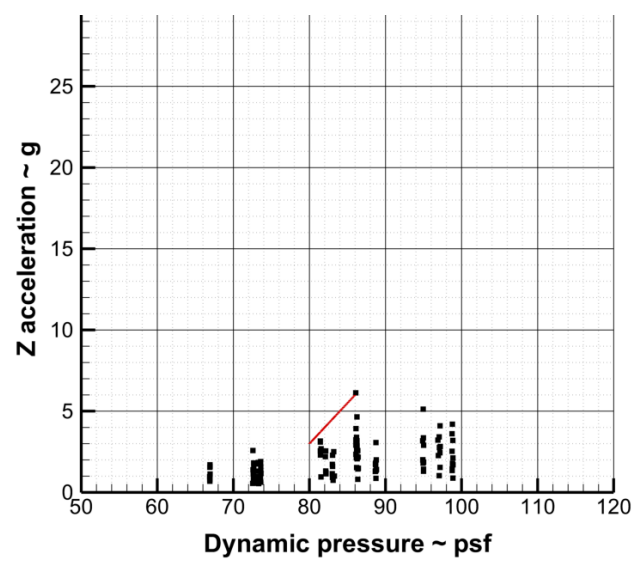

(a) all data

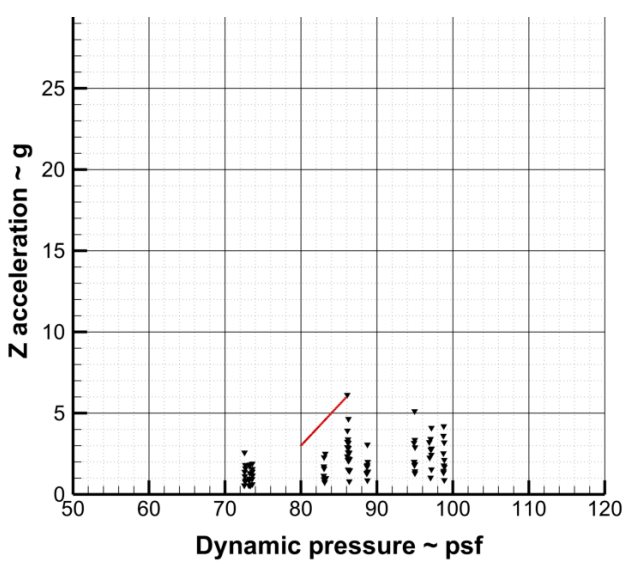

(b) modified-model data

Figure 16. LCO amplitudes, Mach 0.77-0.78, AoA = +3 degree (black symbols - wind-tunnel data, red line - envelope enclosing data).

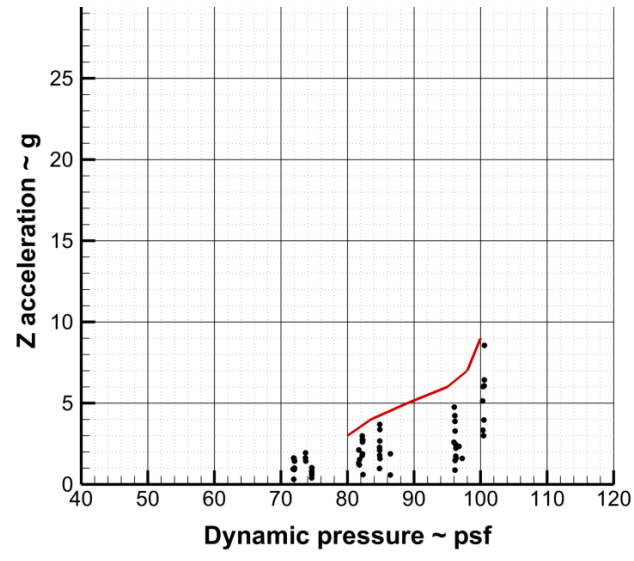

(a) all data

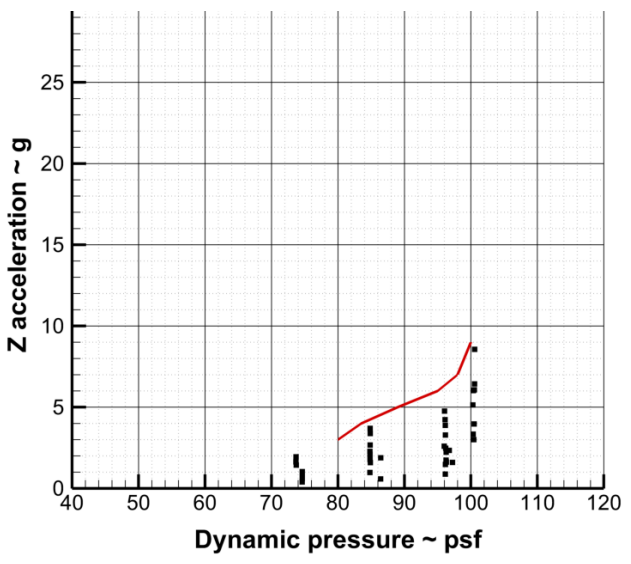

(b) modified-model data

Figure 17. LCO amplitudes, Mach 0.78-0.80, AoA = +3 degree (black symbols - wind-tunnel data, red line - envelope enclosing data).

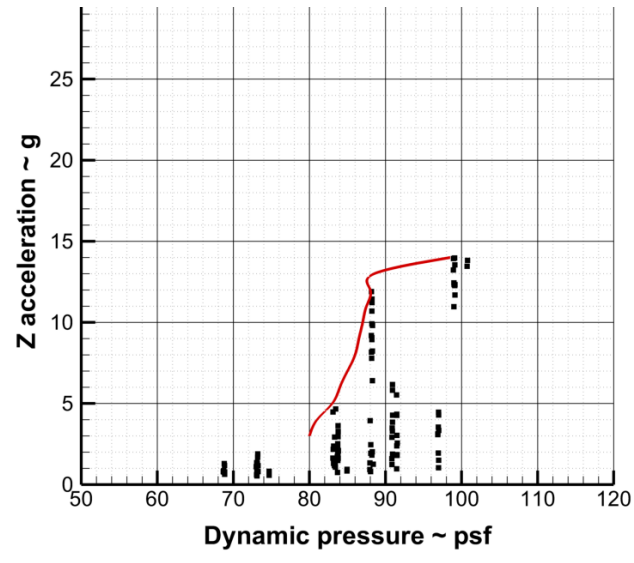

(a) all data

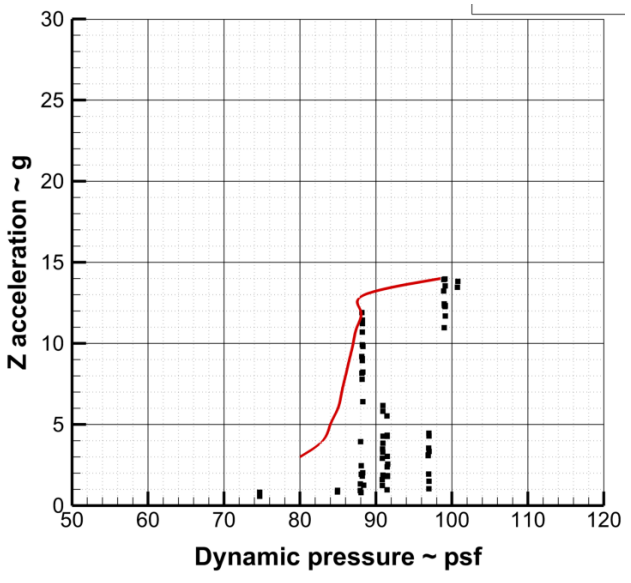

(b) modified-model data

Figure 18. LCO amplitudes, Mach 0.80-0.81, $\mathrm{AoA}=+3$ degree (black symbols - wind-tunnel data, red line - envelope enclosing data). 


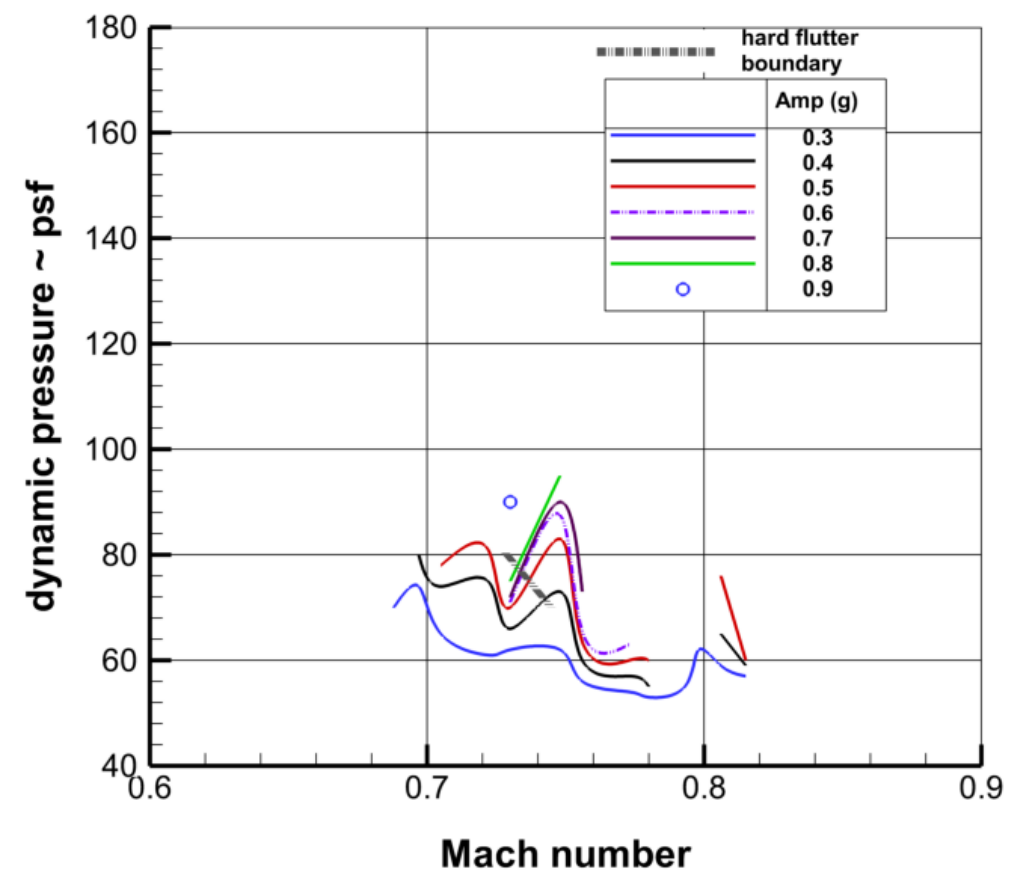

(a) all data

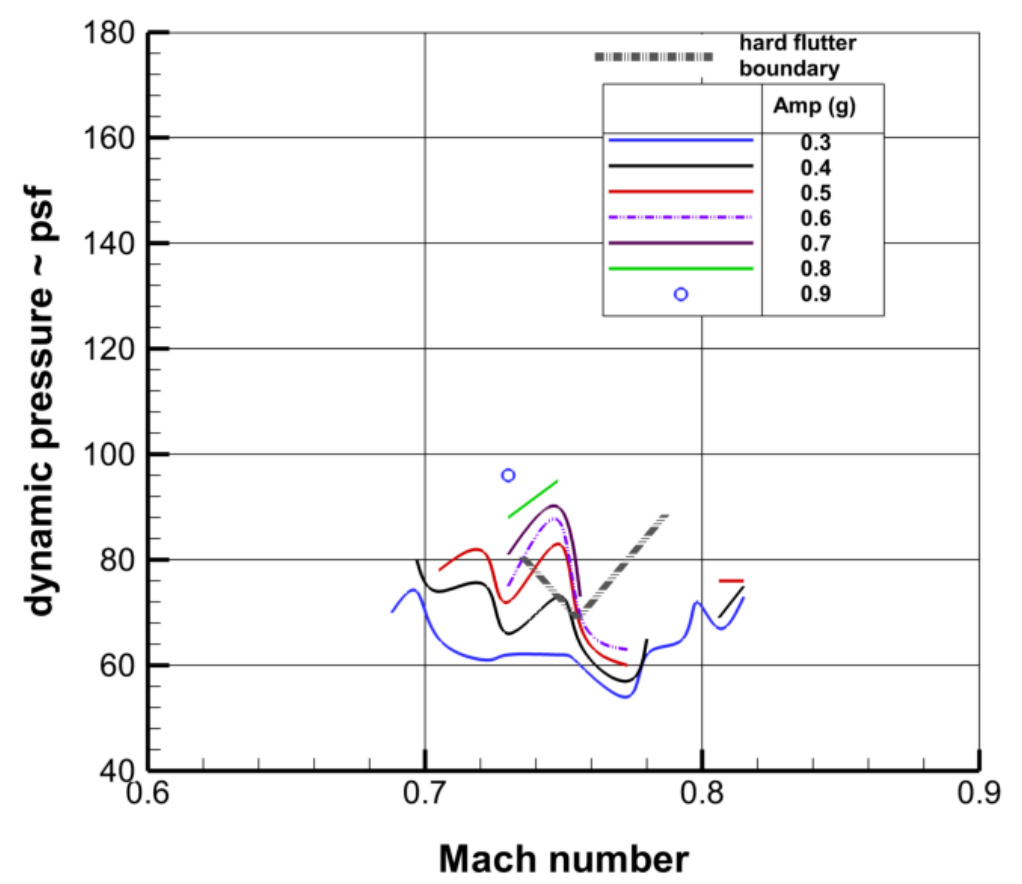

(b) modified-model data

Figure 19. Amplitudes of $10 \mathrm{~Hz}$ nacelle z-acceleration, $\mathrm{AoA}=-\mathbf{3}$ degree. 


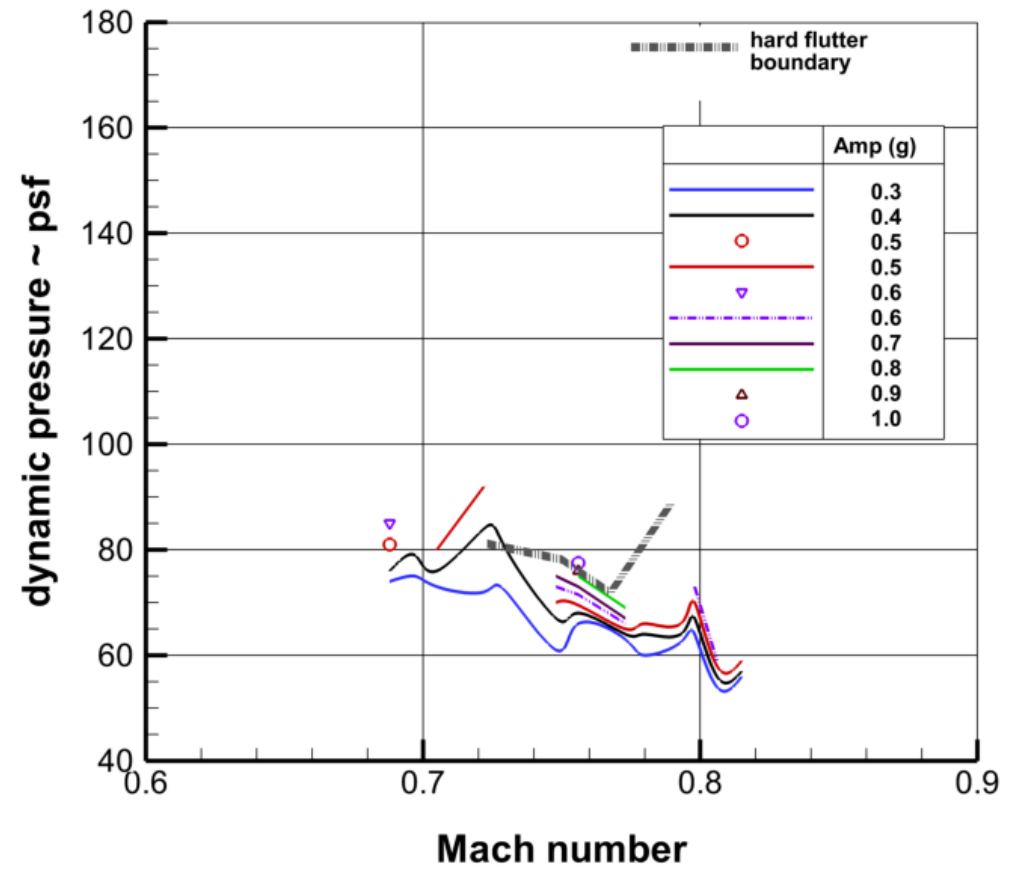

(a) all data

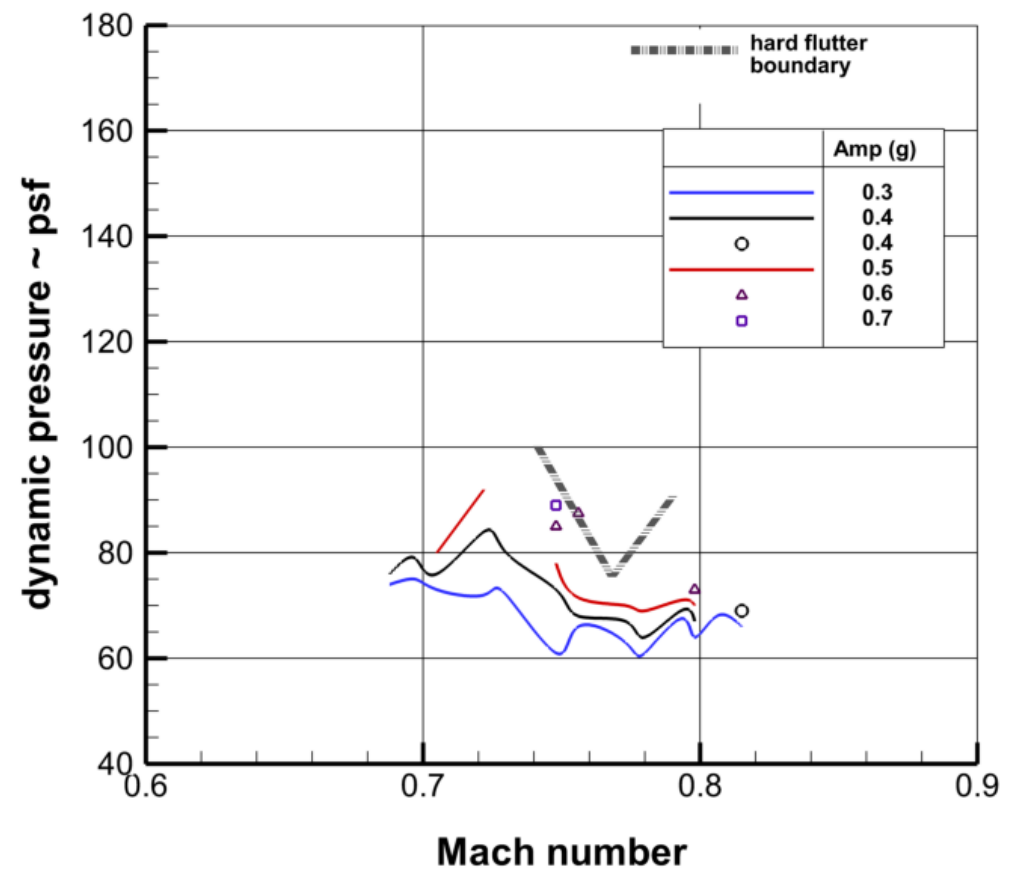

(b) modified-model data

Figure 20. Amplitudes of $10 \mathrm{~Hz}$ nacelle z-acceleration, $\mathrm{AoA}=-1$ degree. 


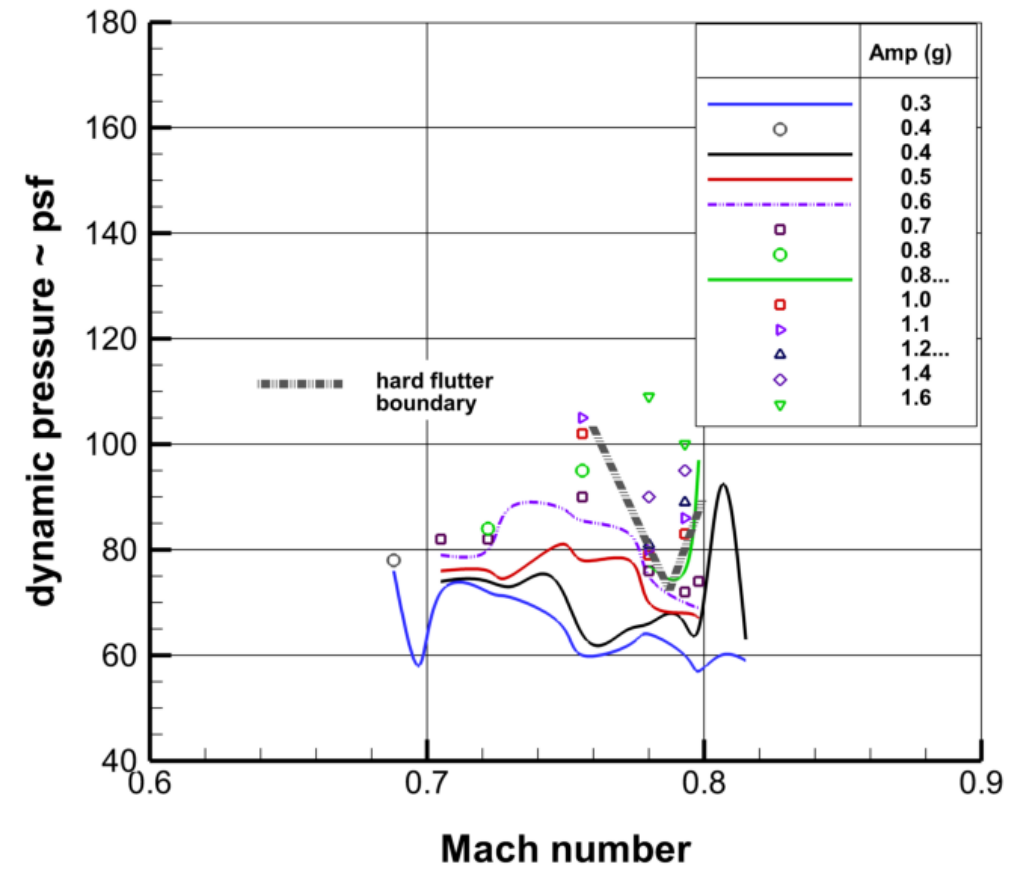

(a) all data

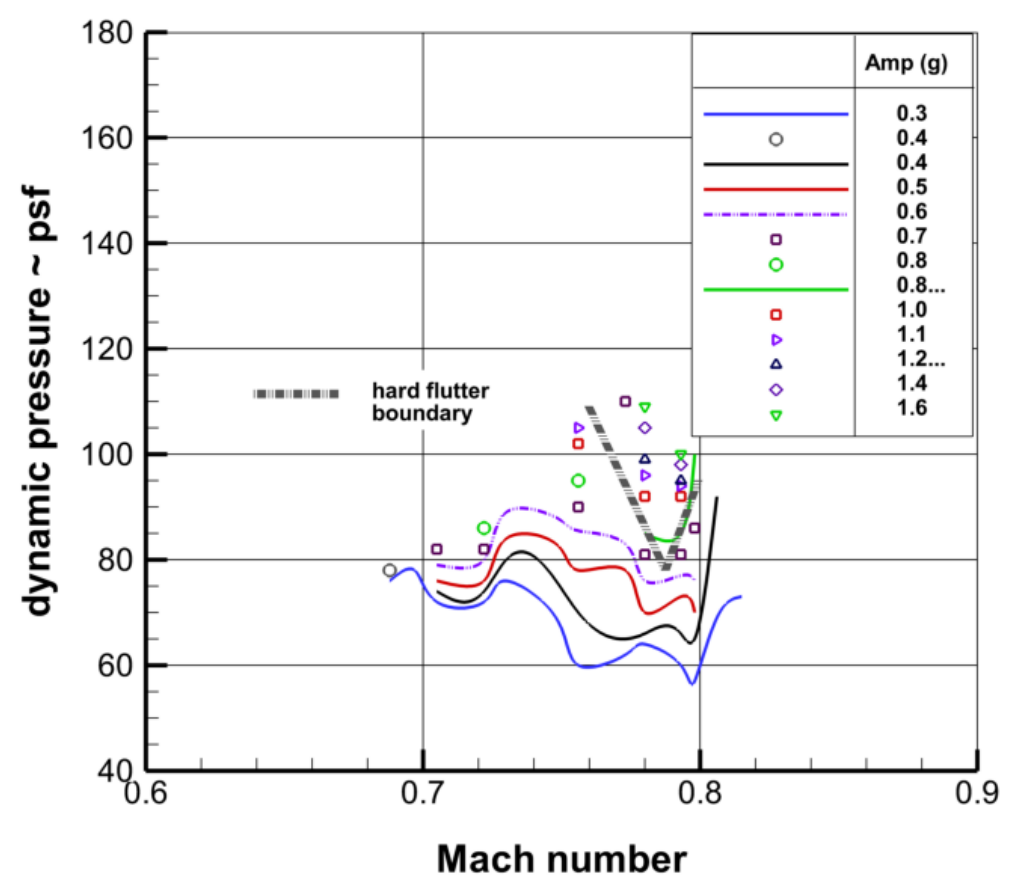

(b) modified-model data

Figure 21. Amplitudes of $10 \mathrm{~Hz}$ nacelle $\mathrm{z}$-acceleration, $\mathrm{AoA}=+1$ degree. 


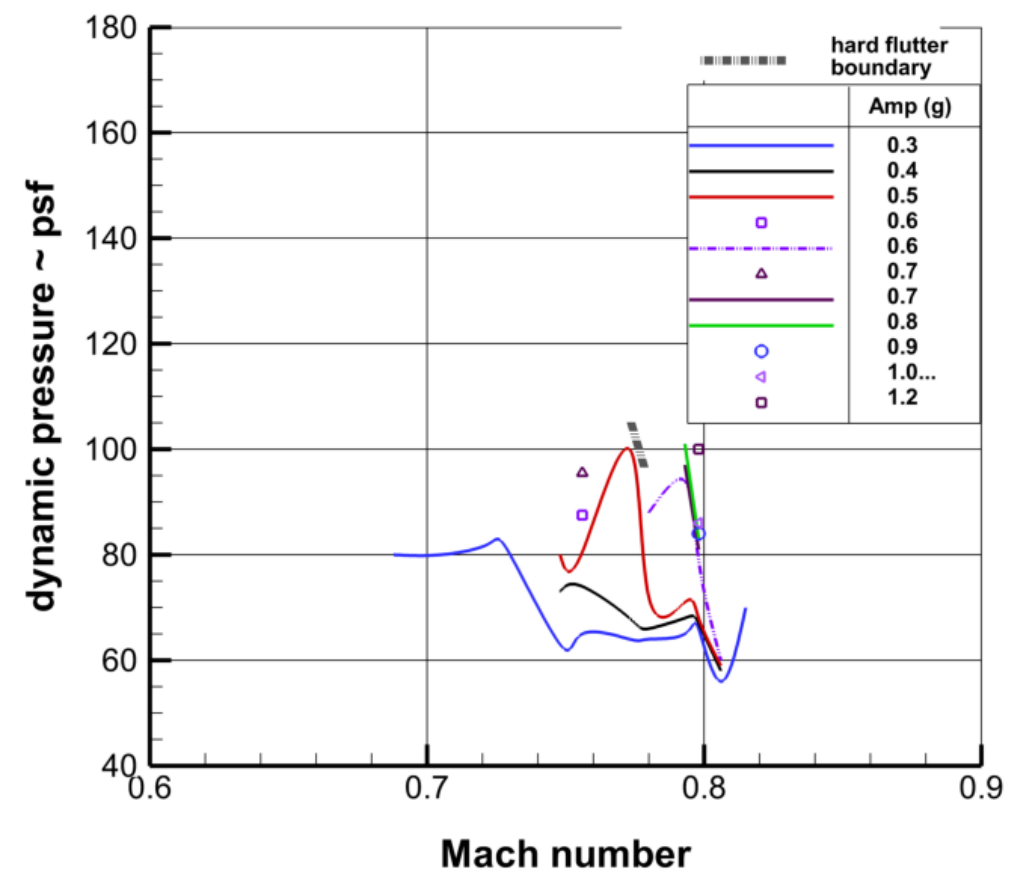

(a) all data

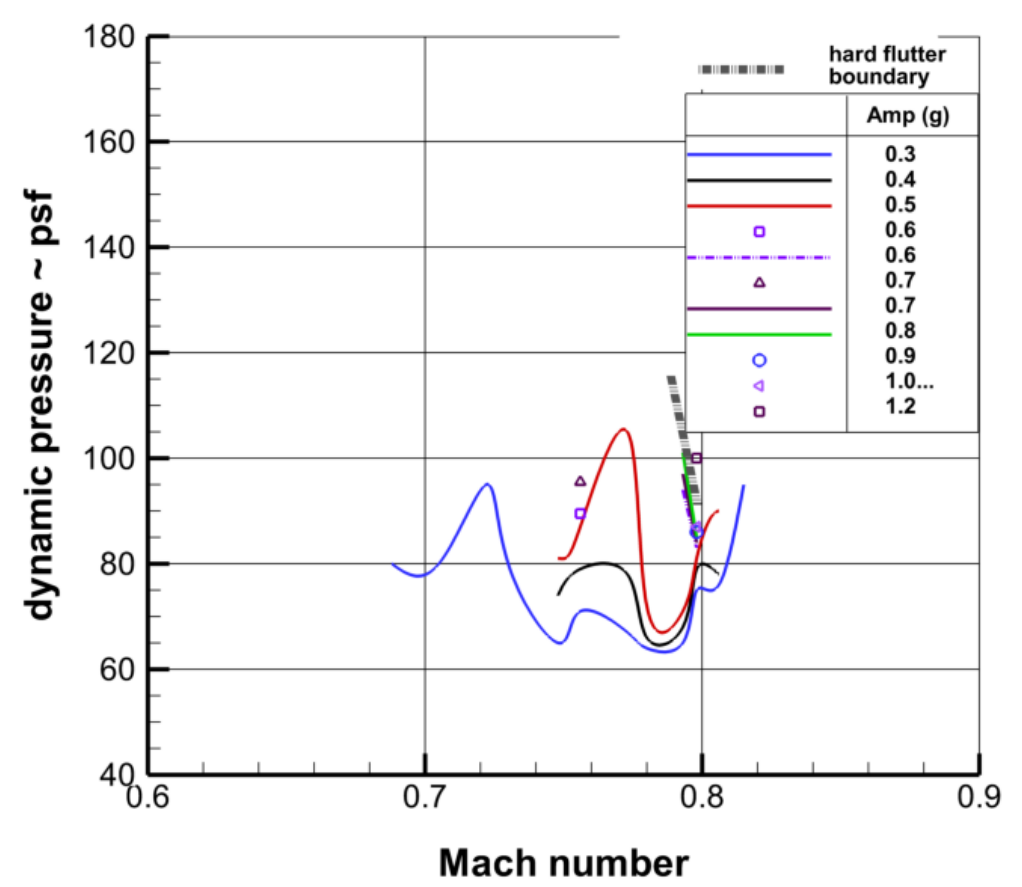

(b) modified-model data

Figure 22. Amplitudes of $10 \mathrm{~Hz}$ nacelle $\mathrm{z}$-acceleration, $\mathrm{AoA}=+3$ degree. 


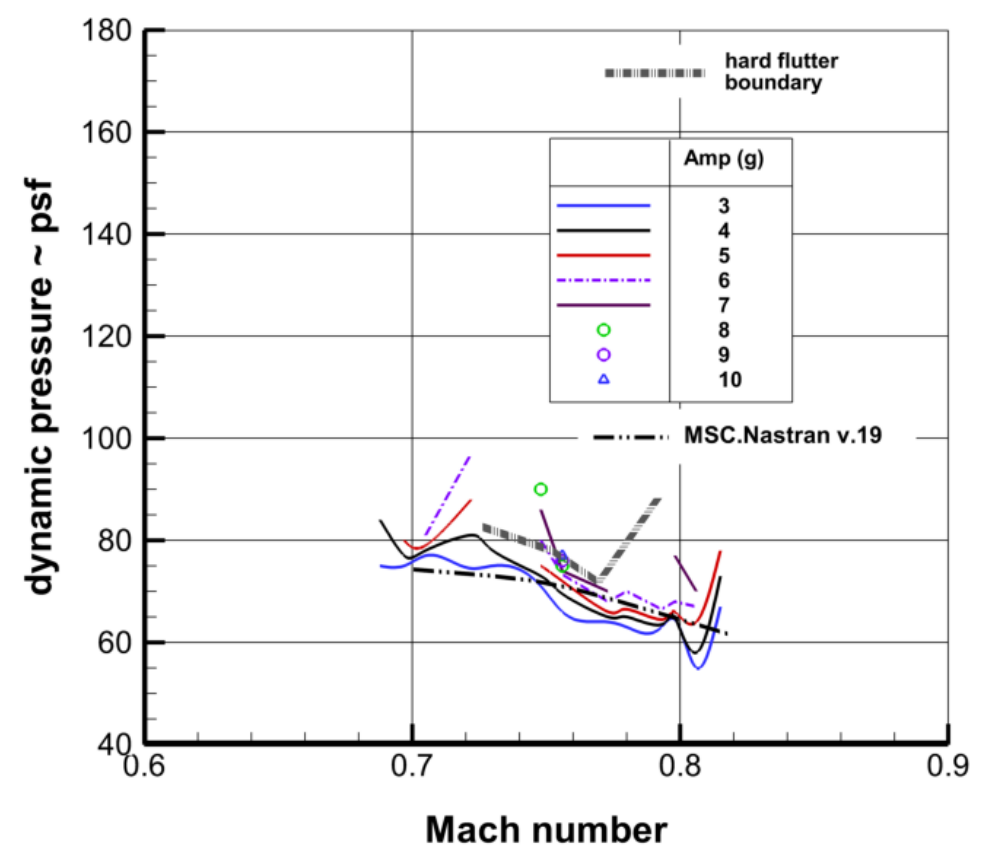

(a) all data

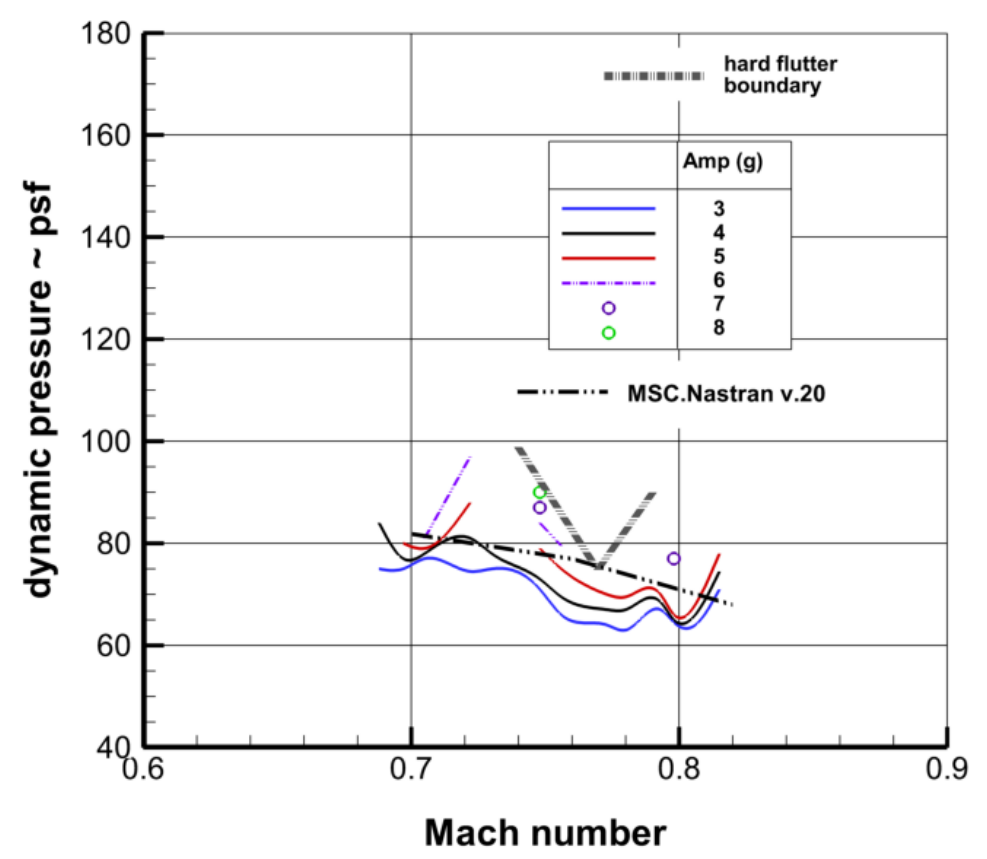

(b) modified-model data

Figure 23. Amplitudes of $10 \mathrm{~Hz}$ forward wing-tip z-acceleration with MSC.Nastran flutter onset, $\mathrm{AoA}=\mathbf{- 1}$ degree. 